\title{
Nitric Oxide Overproduction by cue1 Mutants Differs on Developmental Stages and Growth Conditions
}

\author{
Tamara Lechón, Luis Sanz, Inmaculada Sánchez-Vicente $\mathbb{D}$ and Oscar Lorenzo * $\mathbb{1}$ \\ Department of Botany and Plant Physiology, Instituto Hispano-Luso de Investigaciones Agrarias (CIALE), \\ Facultad de Biología, Universidad de Salamanca, C/Río Duero 12, 37185 Salamanca, Spain; tlg@usal.es (T.L.); \\ lusan@usal.es (L.S.); elfik@usal.es (I.S.-V.) \\ * Correspondence: oslo@usal.es; Tel.: +34-923294500-5117
}

Received: 29 September 2020; Accepted: 2 November 2020; Published: 4 November 2020

\begin{abstract}
The cue1 nitric oxide (NO) overproducer mutants are impaired in a plastid phosphoenolpyruvate/phosphate translocator, mainly expressed in Arabidopsis thaliana roots. cue1 mutants present an increased content of arginine, a precursor of $\mathrm{NO}$ in oxidative synthesis processes. However, the pathways of plant NO biosynthesis and signaling have not yet been fully characterized, and the role of CUE1 in these processes is not clear. Here, in an attempt to advance our knowledge regarding NO homeostasis, we performed a deep characterization of the NO production of four different cue1 alleles (cue1-1, cue1-5, cue1-6 and nox1) during seed germination, primary root elongation, and salt stress resistance. Furthermore, we analyzed the production of NO in different carbon sources to improve our understanding of the interplay between carbon metabolism and NO homeostasis. After in vivo NO imaging and spectrofluorometric quantification of the endogenous NO levels of cue1 mutants, we demonstrate that CUE1 does not directly contribute to the rapid NO synthesis during seed imbibition. Although cue1 mutants do not overproduce NO during germination and early plant development, they are able to accumulate NO after the seedling is completely established. Thus, CUE1 regulates NO homeostasis during post-germinative growth to modulate root development in response to carbon metabolism, as different sugars modify root elongation and meristem organization in cue1 mutants. Therefore, cue1 mutants are a useful tool to study the physiological effects of $\mathrm{NO}$ in post-germinative growth.
\end{abstract}

Keywords: nitric oxide homeostasis; cue1/nox1; reactive nitrogen species; germination; root development; stress responses; sugar metabolism

\section{Introduction}

Since the establishment of nitric oxide (NO) as an endogenous signaling molecule in plants over twenty years ago [1-4], a lot of progress has been made towards understanding NO synthesis and signaling in these organisms. In contrast to other eukaryotes, at least seven different sources of NO generation have been characterized in plants [5-8]. While in mammalian cells NO is synthesized from either nitrite or arginine oxidation in a reaction catalyzed by the enzyme NO synthase [9]; in plants, the existence of this last pathway is controversial [5,10]. Plant NO synthesis is controlled by a number of enzymatic synthesis reactions, catalyzed by the enzyme nitrate reductase, by the mitochondrial electron transport chain, or by the enzyme xanthine amine oxidoreductase during anaerobic conditions (reviewed in [5-11]). Moreover, NO can also be produced non-enzymatically, from acid solutions of nitrite in the presence of compounds that can act as antioxidants [12]. However, we only identified some of the components implicated in the different pathways and it is still unknown how they interact, how they fit in the larger context of carbon and nitrogen metabolism, and how much they contribute to the general NO homeostasis of the plant. The concentration of NO is also tightly regulated through the 
interactions of NO with other compounds, such as reactive oxygen species (ROS), proteins or lipids. Because of its physicochemical characteristics, NO exerts its functions mainly through modification of these molecules, leading to changes in protein activity, gene expression, and modulation of the redox environment, both during physiological and stress responses (reviewed in [6-8,13]). In an attempt to answer these fundamental questions about when and where NO is produced, researchers have used both pharmacological and genetic approaches.

The use of pharmaceutical NO donors such as sodium nitroprusside (SNP), S-nitroso-N-acetyl-D,L-penicillamine (SNAP), or S-nitrosoglutathione (GSNO), although very extended, does not always replicate the endogenous effects of NO. SNP is in fact a nitrosonium cation donor that also generates cyanide [14]. On the other hand, SNAP and GSNO, in addition to releasing NO, can act mainly through trans-S-nitrosation reactions. Furthermore, the application of NO donors might result in nitrosative stress since there have been very few attempts to understand the kinetics of $\mathrm{NO}$ generation in planta by NO donors [15-17]. Thus, the use of mutants with altered endogenous NO content seems to be a more suitable way of assessing NO-modulated responses.

In Arabidopsis thaliana, only four groups of $\mathrm{NO}$ overproducer mutants have been described so far, gsnor1/hot5, glb, argah, and cue1/nox1 mutants. gsnor1/hot5 mutants accumulate GSNO, since they are defective in the enzyme $S$-nitrosoglutathione reductase 1 (GSNOR1) [18], responsible for the degradation of GSNO, a stable NO reservoir, to glutathione disulfide (GSSG) and ammonium [19]. Thus, gsnorl mutants accumulate both NO and GSNO [20]. The glb mutants are also impaired in a NO scavenging system, since they have reduced levels of non-symbiotic hemoglobins, which usually eliminate NO by binding it to their heme group [21]. The last two groups, argah and cue1, are both thought to be implicated in the oxidative synthesis of NO from arginine [22,23]. argah mutants have decreased arginase activity, which results in an increase in the available arginine pool, since arginases control the catabolism of this amino acid. This, in turn, leads to the accumulation of NO in these mutants [22].

The first $A$. thaliana cue1 mutant was isolated in a screening to identify new mutants in light signaling components with an altered light-regulated expression of nuclear genes [24]. CUE stands for 'chlorophyll $a / b$ binding protein $(C A B)$ underexpressed' because mutations at this locus result in expression defects of photosynthesis genes in mesophyll cells, such as the light-harvesting chlorophyll $a / b$-binding protein 1 (LHCB1) of photosystem II, formerly known as CAB. Besides cue1, another eight cue mutants were isolated [25]. All of them are defective in greening and present an altered mesophyll structure. These defects result from a delayed differentiation of chloroplasts and a reduction in plastid size and granal stack size, along with defective etioplast development [25]. In cue1, LHCB1 is expressed at low levels in the mesophyll cell layers but at wild-type levels in the bundle sheath cells, which causes a striking reticulate leaf phenotype with pale-green mesophyll cells and dark-green veins. At the same time, it entails a severe deficiency in the establishment of photoautotrophic growth because of the lack of sufficient carotenoids and chlorophylls, especially during early leaf development in response to light [24].

Of the nine CUE genes, only CUE1 does not directly take part in the phytochrome-controlled expression of photosynthetic genes $[25,26]$. Instead, CUE1 encodes plastid phosphoenolpyruvate (PEP)/phosphate translocator (PPT) expressed mainly in roots, but also in leaves and flowers [27]. PEP is the precursor for the shikimate pathway of aromatic amino acids and can be utilized as an alternative source for ATP in non-photosynthetic plastids. Most plastids either lack or have a very low expression of the complete set of glycolytic enzymes for the conversion of hexose and triose phosphates into PEP, so glycolysis cannot proceed further than 3-phosphoglycerate. PPT is thus the only source of PEP in the chloroplast stroma [28]. In line with this role, cue1 mutants present an altered content of several amino acids and secondary metabolites. Among them, there is an increase in nitrate, arginine and two products of arginine catabolism, citrulline and urea [27].

Both nitrate and arginine are precursors of $\mathrm{NO}$ biosynthesis [29], so it was to be expected that cue1 mutants also showed increased NO content. Indeed, in screening for NO overproducer (nox) 
mutants, the locus NOX1 was identified as CUE1 [23]. The isolation of putative nox mutants was based on their hypersensitivity to root growth inhibition by NO donor SNP. nox1/cue1 was confirmed to have higher levels of NO in rosette leaves when analyzed with $\mathrm{NO}$-sensitive dye 4,5-diaminofluorescein diacetate (DAF-2DA). Since then, cue1 mutants have been described to have delayed flowering [23], smaller rosettes, leaves and cotyledons [30], increased stomatal development [31], reduced root length and meristem size [32-34], decreased mitosis and increased endoreduplication [32,35], reduced auxin response [32], decreased cytokinin content [36], higher iron uptake [37], better copper tolerance [38], and less pathogen resistance [39-41].

Because cue1 mutants display a complex pleiotropic phenotype, understanding the role of CUE1/PPT1 in NO synthesis and signaling is not trivial. Here, we sought to establish the growth conditions in which cue1 mutants overproduce NO and to identify which phenotypes can be unequivocally ascribed to an altered NO homeostasis in order to close the current gap between pharmacological and genetic studies. For this purpose, we analyzed the phenotype of four different cue1 alleles during physiological processes and stress responses in which NO is known to have an important role: promotion of germination [42-45], inhibition of primary root elongation [23,32,33], and improvement of salt stress resistance [46-48]. This was done alongside the in vivo NO imaging and quantification of the NO content of each mutant by spectrofluorometry using the fluorescent NO-sensing dye 4-amino-5-methylamino-2', $7^{\prime}$-difluorofluorescein diacetate (DAF-FM DA) according to the method described in [49], to find out if there is a link between NO levels and the observed phenotypes. Furthermore, we analyzed the production of NO in different carbon sources to improve our understanding of the interplay between carbon metabolism and NO homeostasis, for which cue1 mutants are an excellent model, as the primary role of PPT1 is likely to be related to glycolysis and gluconeogenesis in the plastids.

\section{Results}

\section{1. cue1 Mutants Accumulate Wild-Type NO Levels during Early Post-Germinative Plant Development}

A rapid increase in NO levels appears in the endosperm of $A$. thaliana seeds after imbibition [50]. NO then promotes germination both by relieving dormancy $[42,51]$ and by directly promoting embryo growth [45]. In order to study the response of cue1 mutants during germination, we chose four different knockdown and knockout alleles that have been extensively used in the literature and are known to have increased NO in rosette leaves [23,31,36,39,40] (Figure 1A). Three of the alleles come from a mutagenized Col-0 line, cue1-5, cue1-6, and nox1-1. cue1-5 is a weak allele with an Arg to Cys point mutation [27], cue1-6 is a strong allele with a premature stop codon instead of a Trp caused by a point mutation [27], and nox1-1 is a knockout mutant which was obtained by fast neutron mutagenesis and lacks most of the genomic CUE1/PPT1 sequence [23]. cue1-1 is another deletion mutant, but it was obtained by gamma radiation mutagenesis of a transgenic line, pOCA108 (Be-0), that is also an alcohol dehydrogenase null mutant [24].

Although these mutants are routinely used as constitutive NO-overproducer mutants, there is no data on their NO levels during early plant development. While the link between PPT1, light signaling, and NO production is not understood, it is known that CUE1 strongly regulates the expression of LHBC and other photosynthetic genes when plants are initially exposed to light, but cue 1 mutants show a greater degree of plasticity at later stages of development [27]. Therefore, we quantified the NO content of the four alleles and their respective wild-type controls 4 days after completion of stratification (das), once the radicle was visible in most of the seeds in the population. Contrary to what was expected, all four cue1 alleles had similar or less DAF fluorescence than their respective controls, suggesting that the mutants do not overproduce NO at this developmental stage. cue1-6 and nox 1 had the same fluorescence intensity than Col-0 (0.77 \pm 0.01 a.f.u./ $\mu$ g protein and $0.74 \pm 0.01$ a.f.u./ $\mu$ g protein compared to $0.72 \pm 0.05$ a.f.u./ $\mu$ g protein), whereas cue1-5 $(0.49 \pm 0.05$ a.f.u./ $\mu$ g protein) 
had $36 \%$ less than Col-0 $(p<0.001)$ and cue1-1 $(0.68 \pm 0.06$ a.f.u./mg protein $), 25 \%$ less than pOCA108 $(0.91 \pm 0.05$ a.f.u./ $/ \mu$ p protein; $p<0.001)$ (Figure 1B).

A

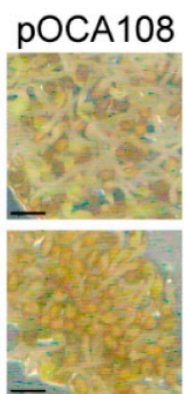

cue1-1

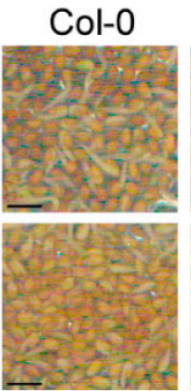

nox1

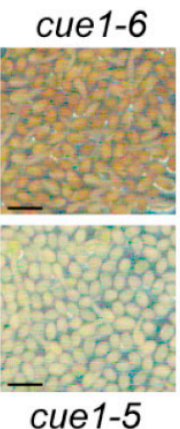

B

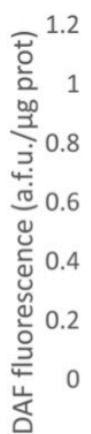

NO Content of 4-day-old Seedlings

- Control $=\mathrm{NaCl}$

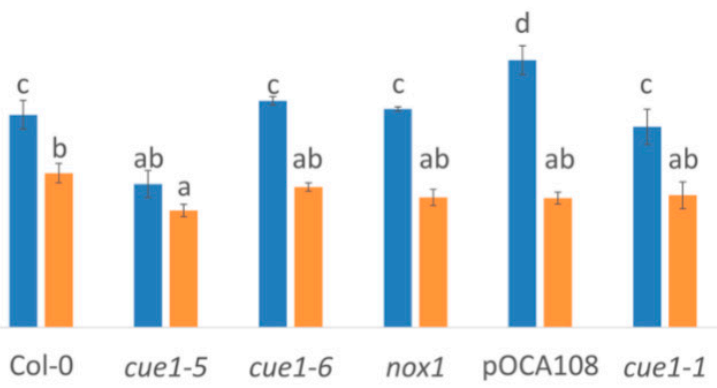

Figure 1. Phenotype (A) and nitric oxide (NO) content (B) of 4-day-old seedlings. Scale bar, $1 \mathrm{~mm}$. DAF fluorescence intensity of extracts of 4-day-old seedlings grown on Murashige and Skoog (MS) with and without $100 \mathrm{mM} \mathrm{NaCl}$. Values represent the mean $\pm \mathrm{CI}(n=3)$. Bars with common letters (a-d) do not show significant statistical differences. A two-way analysis of variance (ANOVA) with post-hoc Tukey's honestly significance difference (HSD) test showed a statistically significant interaction between genotype and salinity $\left(\left(\mathrm{F}_{(5,24)}=23.13, p<0.001\right.\right.$, eta2 $\left.[\mathrm{g}]=0.83\right)$. An analysis of simple main effects for each factor was performed with statistical significance after a Bonferroni correction (Table S2).

High salinity delays germination and impairs seedling establishment [52]. Endogenous NO is increased when plants are exposed to salt stress and might act as an antioxidant by quenching the ROS produced in response to salinity [53-56]. In order to see whether cue1 mutants would accumulate NO during salt stress, we indirectly quantified the NO content of 4-day-old seedlings grown on a medium supplemented with $100 \mathrm{mM} \mathrm{NaCl}$ through quantification of DAF fluorescence. This salt concentration was chosen because it has been previously shown that it is enough to cause salt stress to A. thaliana seedlings [53]. Under our growth conditions, the DAF fluorescence significantly decreased in all the examined lines after salt stress, suggesting an inability to overproduce $\mathrm{NO}$ at this stage (Figure 1). In this case, cue1-5 had $0.4 \pm 0.02$ a.f.u./ $/$ g protein, only $23 \%$ less than Col-0, which had $0.52 \pm 0.03$ a.f.u./ $\mu \mathrm{g}$ protein. The rest of the lines had similar fluorescence levels to those of Col-0, ranging from $0.44 \pm 0.02$ a.f.u./ $\mu$ g protein to $0.47 \pm 0.01$ a.f.u./ $\mu$ g protein. The greatest decrease in the presence of high salinity was observed in pOCA108, which had $48 \%$ of the fluorescence intensity it accumulated in control conditions.

\subsection{NO Is Necessary to Maintain Germination Vigor}

Given the role of NO in the promotion of seed germination [45], we decided to analyze the germination rate of the different cue1 alleles. While most of the Col-0, cue1-6, nox1-1, pOCA108, and cue1-1 seeds had fully germinated after 4 das (between $96.5 \%$ and $99.5 \%$ of the population), the maximum germination $\left(\mathrm{G}_{\max }\right)$ of cue1-5 was only $67 \%$, in accordance with the decrease in DAF fluorescence and supporting a reduced NO content at this stage (Figure 2A). In the presence of high salinity, the germination of all the lines decreased consistently with a reduction in endogenous NO. This germination delay was especially apparent for cue1-5, which had a $G_{\max }$ of $48 \%$ while the rest of the lines had similar $\mathrm{G}_{\max }$ that varied between $66 \%$ and $88 \%$ (Figure 2A). Despite the stark decrease in DAF fluorescence after salt stress (Figure 1), the germination of pOCA108 was almost unaffected by the stress, with only an $11 \%$ decrease in its germination rate with respect to control conditions. 
A
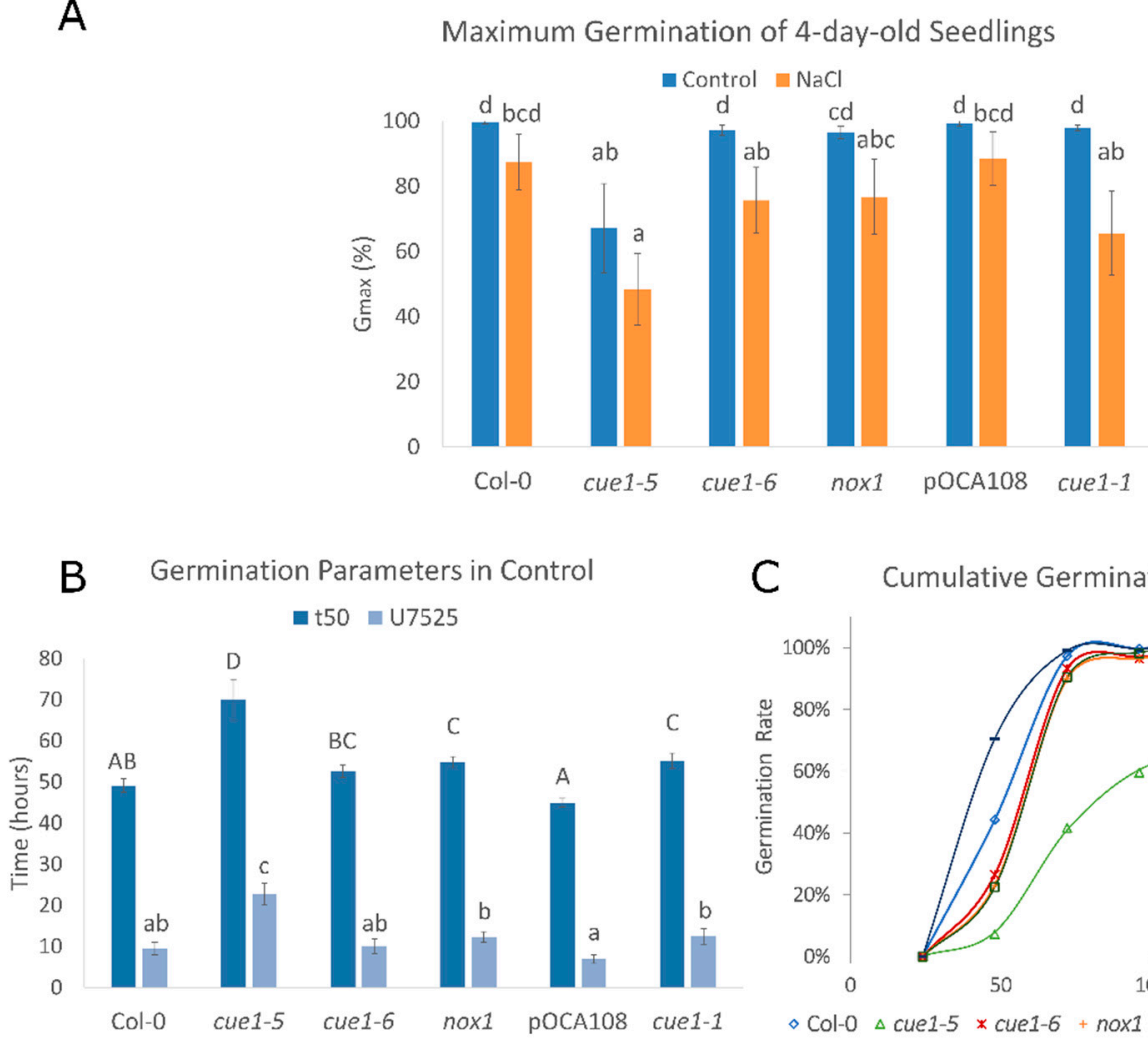

C Cumulative Germination in Control

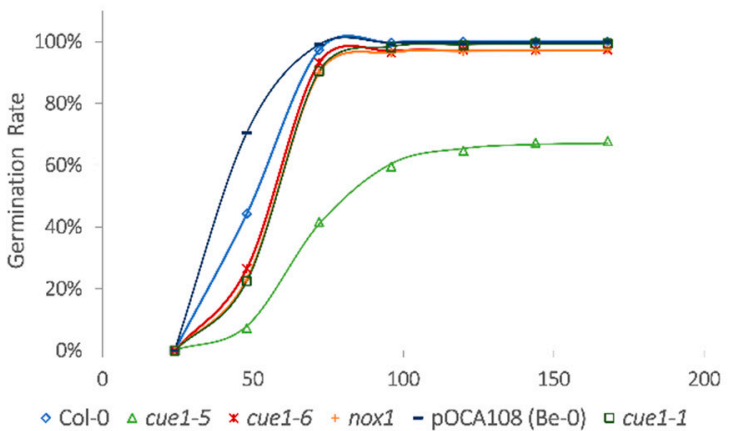

D Germination Parameters in High Salinity at50 $=\mathrm{u} 7525$
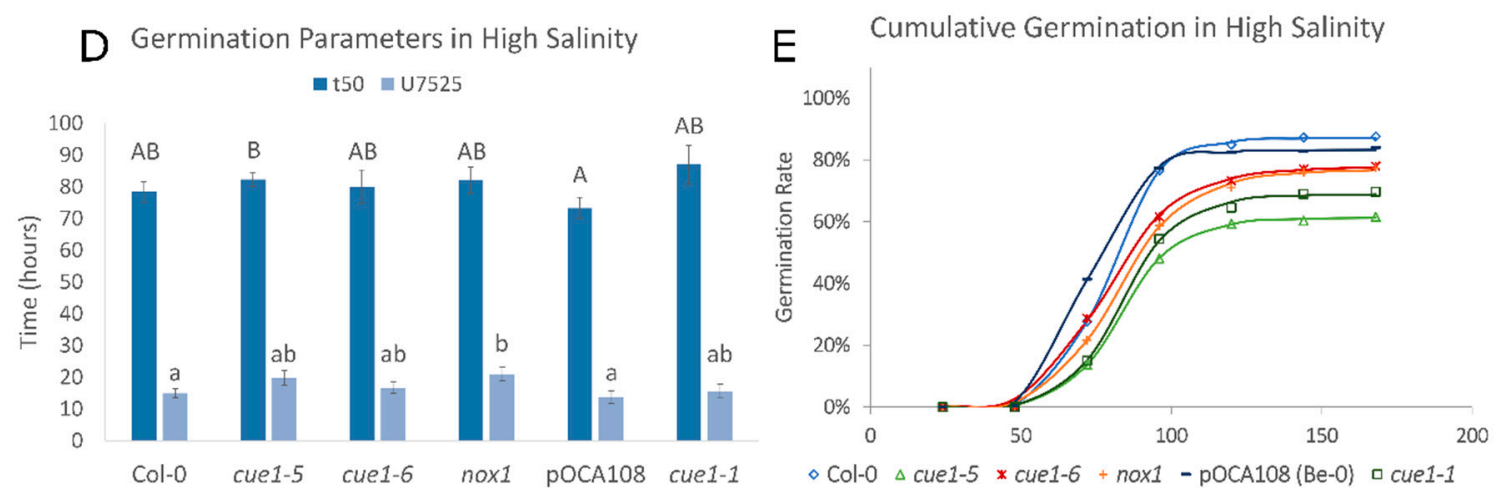

Figure 2. NO is required for germination vigor. Values represent the mean $\pm \mathrm{CI}(n=12)$. Bars with common letters do not show significant statistical differences as determined by the respective statistical tests: (A) Maximum germination of seedlings 4 das with and without $100 \mathrm{mM} \mathrm{NaCl}$. Welch's one-way ANOVA with post-hoc Games-Howell test was $\mathrm{F}_{(5,29)}=7.98 . p<0.001$. (B) Germination parameters $t_{50}$ and $U_{7525}$ for seeds germinated in control conditions. (C) Representative cumulative germination curve for seeds germinated in control conditions as predicted by GERMINATOR. (D) Germination parameters $t_{50}$ and $U_{7525}$ for seeds exposed to high salinity. (E) Representative cumulative germination curve for seeds germinated in the presence of $100 \mathrm{mM} \mathrm{NaCl}$ as predicted by GERMINATOR.

The speed and uniformity of germination were analyzed using $t_{50}$ and $U_{7525} . t_{50}$ is a parameter that summarizes the time required for $50 \%$ of the viable seeds to germinate [57]. We found an inverse correlation between DAF fluorescence and speed germination parameter $t_{50}(r=-0.94, p<0.001)$. It took $69.99 \pm 4.96 \mathrm{~h}$ for half of the cue1-5 seeds to germinate, whereas the $t_{50}$ of Col- 0 was only $49.12 \pm 1.69 \mathrm{~h}, 30 \%$ faster than the mutant. Equally, the $t_{50}$ of pOCA108 was $44.92 \pm 1.04 \mathrm{~h}, 19 \%$ faster than that of cue1-1, $55.19 \pm 1.8 \mathrm{~h}$ (Figure 2B). $\mathrm{U}_{7525}$ measures the time interval between the germination of $25 \%$ and $75 \%$ of the viable seeds. A lower $U_{7525}$ indicates greater uniformity [58]. The analysis of 
uniformity supported an inverse correlation between NO levels and germination $(r=-0.87, p<0.001)$. The $\mathrm{U}_{7525}$ of cue $1-5$ was $22.65 \pm 2.64 \mathrm{~h}, 13.16 \mathrm{~h}$ longer than its control, while on the other end of the spectrum pOCA108 had a $\mathrm{U}_{7525}$ of $6.9 \pm 1.03 \mathrm{~h}$ (Figure 2B). These results suggest that a certain level of $\mathrm{NO}$ is necessary for seeds to germinate uniformly once dormancy is broken. Cumulative germination over 7 das showed a similar exponential curve for Col-0 and pOCA108, with a steeper slope for pOCA108, the line that showed the highest endogenous NO levels. On the other hand, all cue 1 mutants showed a longer lag phase that lasted up to $48 \mathrm{~h}$ after completion of stratification, which suggests that endogenous NO levels might be even lower in cue 1 mutants prior to radicle emergence (Figure 2C).

In the presence of high salinity, the $t_{50}$ and $U_{7525}$ of all the lines were similar (Figure 2D), in agreement with their similarity in NO production (Figure 1). While cue1-1 seemed to have the highest $\mathrm{t}_{50}$ at $87.0 \pm 6.1 \mathrm{~h}$, this difference was not significant when compared to its control or other lines, which showed $t_{50}$ ranging from $73.4 \pm 3.3 \mathrm{~h}$ to $82.3 \pm 2.0 \mathrm{~h}$. Even though germination was generally slower under salt stress, uniformity of germination was more stable for all genotypes. Control lines had slightly more uniform germination with a $\mathrm{U}_{7525}$ of $15.0 \pm 1.4 \mathrm{~h}$ for Col- 0 and $13.8 \pm 1.9 \mathrm{~h}$ for pOCA108, while the $\mathrm{U}_{7525}$ of the cue 1 mutants ranged between $15.6 \pm 2.2 \mathrm{~h}$ and $21.0 \pm 2.1 \mathrm{~h}$. The analysis of cumulative germination showed that all the lines had a longer lag phase in the presence of salt stress than in control conditions (Figure 2E, compare to Figure 2C).

\subsection{The Severe Germination Delay of cue1-5 Is Caused by Stabilization of the Germination Repressor ABI5}

The plant hormone abscisic acid (ABA) maintains dormancy and post-germinative seedling arrest under unfavorable environmental conditions [59]. ABA exerts these functions mainly through the basic leucine zipper (bZIP) transcription factor ABSCISIC ACID INSENSITIVE5 (ABI5), a key repressor of seed germination $[60,61]$. The antagonistic effects of $A B A$ and NO during germination occur through a crosstalk during the regulation of $A B I 5$ transcription [62] and protein stability [45]. NO-mediated $S$-nitrosation of ABI5 at Cys 153 facilitates the degradation of this germination repressor, and it has been proven that ABI5 protein levels are high in NO-deficient mutant backgrounds [45]. As well as during germination, $\mathrm{ABA}$ has a prominent role during the regulation of the response to most abiotic stresses [63]. The regulation of seed germination and seedling establishment in response to stress is also regulated by ABI5, as it has been shown that loss-of-function abi5 mutants were able to germinate and green even in the presence of $200 \mathrm{mM} \mathrm{NaCl}$ [60].

In order to confirm that the germination deficiency observed in the cue1-5 mutant is indeed due to its lack of sufficient NO, we analyzed the protein levels of ABI5 in 4-day-old seedlings. In agreement with the marked NO deficiency of cue1-5 and its inability to reach a similar $\mathrm{G}_{\max }$ to that of the other lines, we found that this mutant accumulated higher ABI5 protein levels (Figure 3). The quantity of ABI5 was comparable in the rest of lines, in accordance with their similar NO levels. Confirming the role of NO in the stability of the protein, we also found equally elevated ABI5 levels in all the lines in the presence of high salinity in the Col-0 background, consistent with the presence of abiotic stress and the decreased NO levels and germination rate.

\subsection{Early Root Elongation Is Impaired in cue1 Mutants Independently of Their NO Levels, but Root Cell Patterning Is Not Altered}

Studies carried out mainly with pharmacological NO donors and scavengers show that both excessive and insufficient NO result in the inhibition of root elongation $[32,33,64,65]$. Analysis of the root length of 5-day-old seedlings showed that all the cue1 mutants had shorter roots than their respective controls (Figure 4A). The root lengths of Col- 0 and pOCA108 were equivalent $(0.85 \pm 0.04 \mathrm{~cm}$ and $0.77 \pm 0.05 \mathrm{~cm}$, respectively), despite their differences in DAF measurements of NO at 4 das. At the same time, the root lengths of cue1-6 and nox 1 were $40 \%$ and $28 \%$ shorter than Col-0, respectively, even though both lines showed as much DAF fluorescence as Col-0. On the other hand, cue1-1 and cue1-5, the mutants that accumulated less NO according to the DAF measurements, also had the shortest primary roots. 


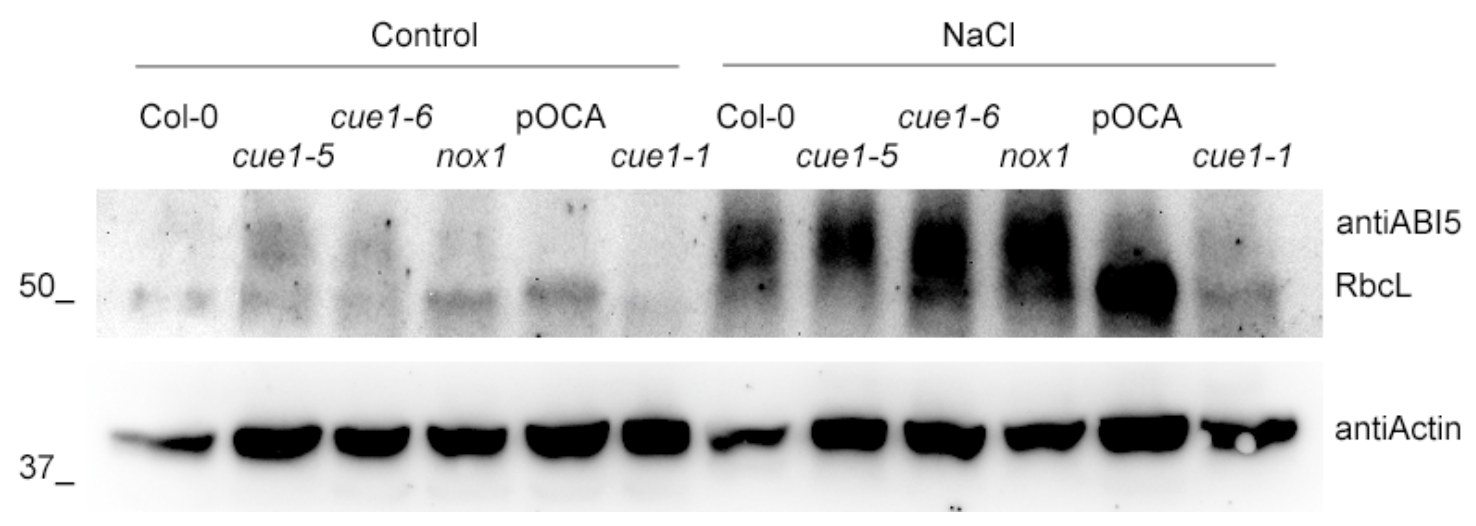

Figure 3. Germination inhibitor ABI5 is stabilized in cue1-5 and in the presence of salt stress. Western blot analysis of ABI5 accumulation in the different cue1 lines grown on MS with and without $100 \mathrm{mM}$ $\mathrm{NaCl}$ for 4 das. Actin levels are shown as loading controls.

The root is organized into cell layers of different cell types that originate from a small set of cells at the core of the root, called the quiescent center (QC). QC cells divide infrequently and maintain the undifferentiated state of the adjacent cells, which are called stem cell initials. Stem cells continuously undergo asymmetric cell divisions that give rise to daughter cells that will divide symmetrically and start to differentiate [66]. This results in clear developmental zones along the longitudinal axis of the root. In the proximal meristem or meristematic zone (MZ), cells divide frequently until they are far enough from the stem cell niche. Once they reach the elongation/differentiation zone (EDZ) they start to expand quickly, beginning the process of differentiation. Maintaining these structures requires a balance between the generation of new cells in the meristem and the differentiation of cells in the EDZ. This balance determines the size of the root apical meristem (RAM) [67]. In accordance with their shorter roots, all the cue1 mutants seemed to have a narrower vascular bundle than both wild-type lines, and a high accumulation of amyloplasts in the epidermis, cortex, and endodermis from the transition zone upwards (Figure 4B). A closer look at the meristematic zone showed that the altered organization of the stem cells around the $Q C$ that has been described to be caused by NO [32] was not apparent at this developmental stage (Figure 4B). This agrees with the fact that cue1 mutants do not overproduce NO 4 days after completion of stratification.

\subsection{Sugar Supplementation Modifies NO Production}

In the absence of CUE1, plants are unable to establish photoautotrophic growth if they are not supplemented with exogenous metabolizable sugars, such as sucrose or glucose [24]. Chloroplasts are an important node of NO production [68], so we wanted to explore whether sugars have a role in NO homeostasis, since there are some reports that point to a possible role for NO in the regulation of energy production [69-71]. We tested the NO levels of cue1-5, cue1-1, and their respective controls after growing them for 7 das in a medium supplemented with either $2 \%(w / v)$ glucose or $0.75 \%(w / v)$ sucrose. Our results show that cue 1 mutants do indeed accumulate $\mathrm{NO}$ at this developmental stage (Figure 5A, Figure S1). 
A Root Length of 5-day-old Seedlings

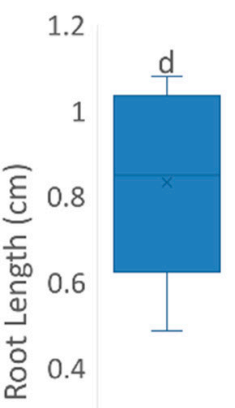

0.2

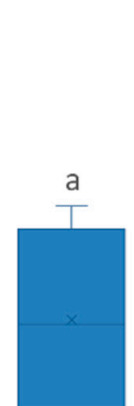

1
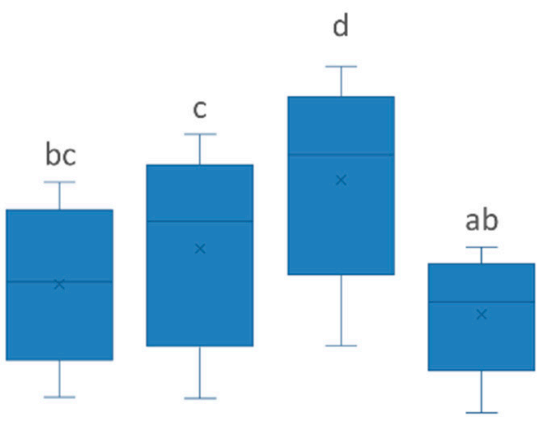

0

B
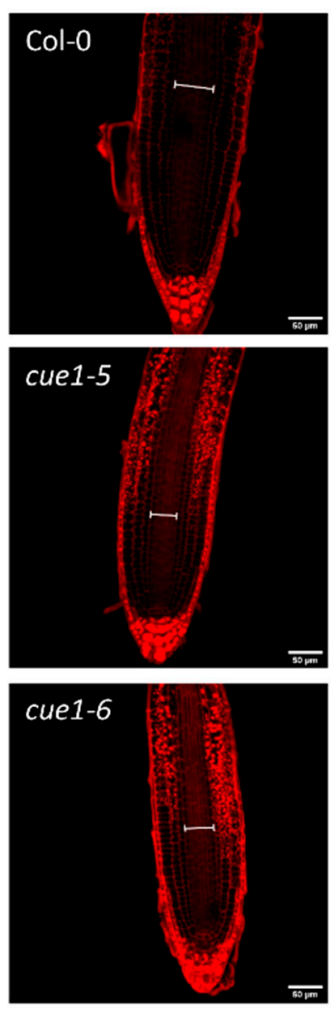

Col-0

cue1-5

cue1-6

nox 1

p0CA108

cue1-1
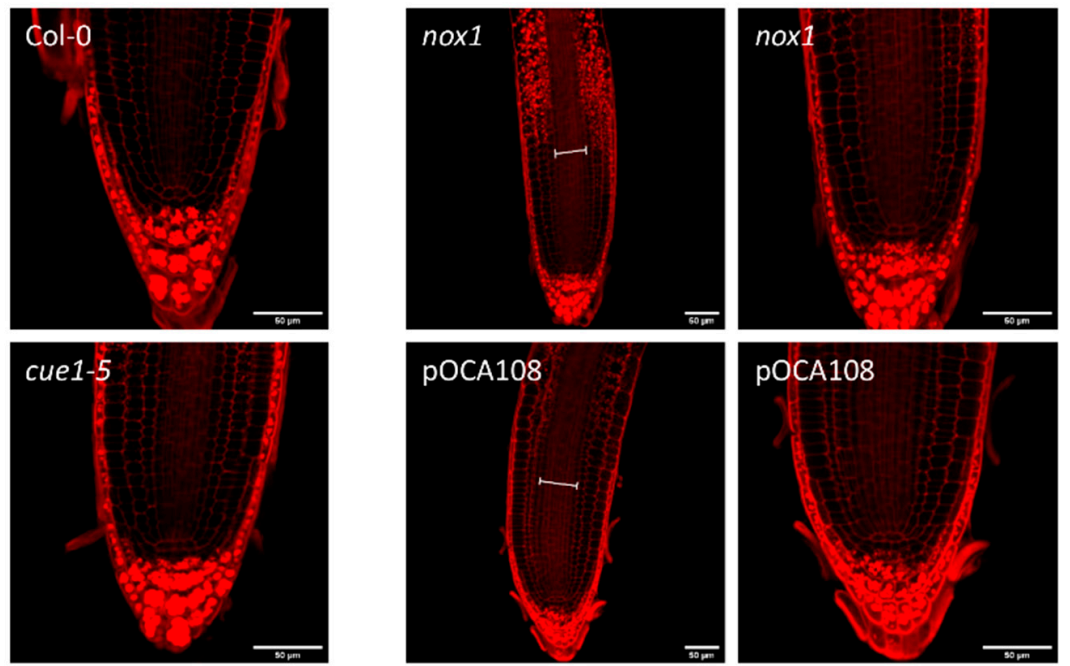

pOCA108
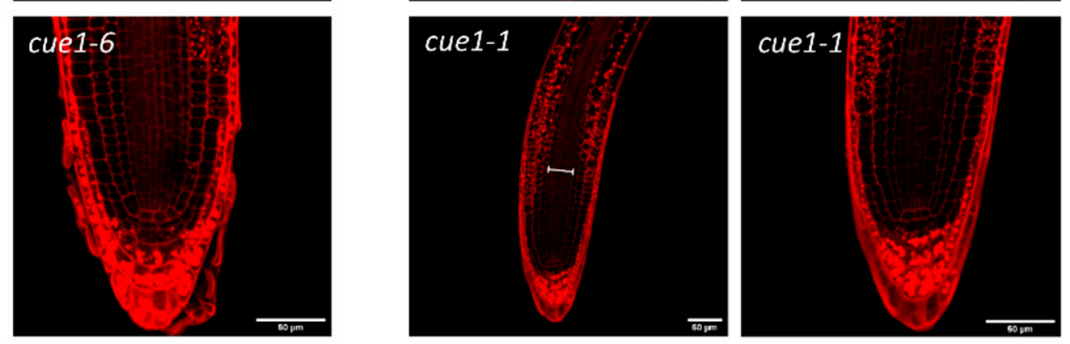

Figure 4. Root elongation is defective in all cue1 mutants. (A) Primary root length of 5-day-old seedlings. The diagram shows data between the lower $(\mathrm{Q} 1)$ and upper $(\mathrm{Q} 3)$ quartiles, the median and the mean $(\mathrm{x})$ for each genotype. Bars with common letters (a-d) do not show significant statistical differences as determined by one-way ANOVA with post-hoc Tukey's HSD test $\left(\mathrm{F}_{(5,214)}=57.8, p<0.001\right)$. (B) Representative images of the root apex of 5-day-old seedlings stained with Schiff propidium iodide. Scale bars on the bottom right corner correspond to $50 \mu \mathrm{m}$. The width of the vascular bundle is indicated with a white line in each root. 
A

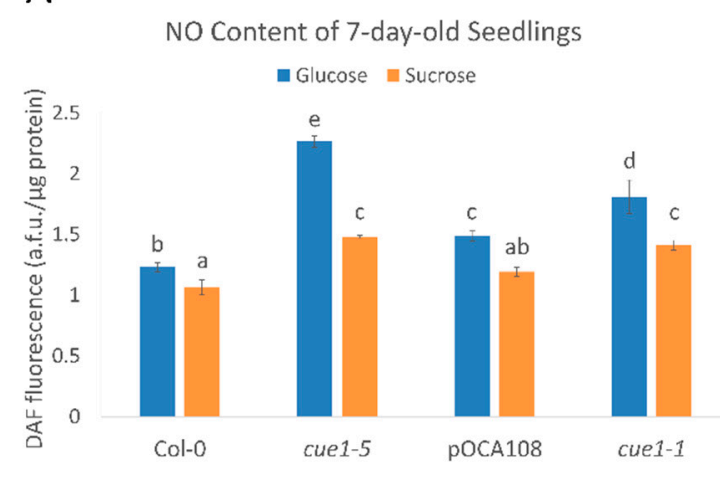

B

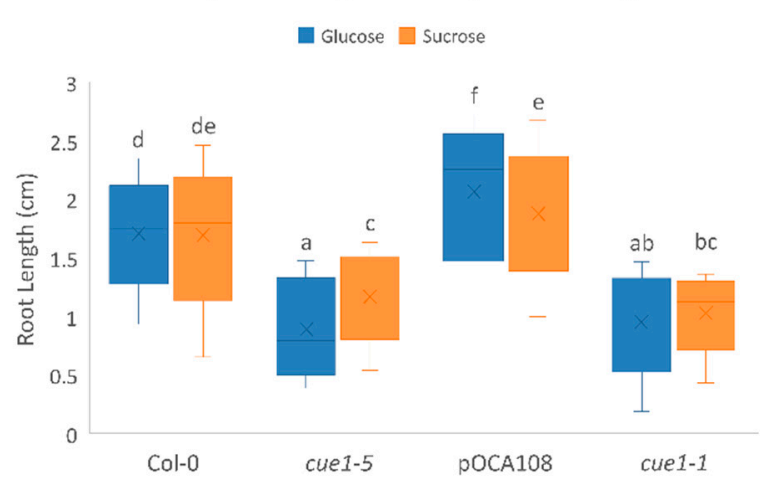

Figure 5. (A) The NO content of cue1 alleles depends on their developmental stage. DAF fluorescence intensity of extracts of 7-day-old seedlings grown on MS-Root medium supplemented with either $2 \%(w / v)$ glucose or $0.75 \%(w / v)$ sucrose. Values represent the mean $\pm \mathrm{CI}(n=4)$. A two-way ANOVA with post-hoc Tukey's HSD test showed a statistically significant interaction between genotype and carbon source $\left(\left(\mathrm{F}_{(3,24)}=33.99, p<0.001\right.\right.$, eta2 $\left.[\mathrm{g}]=0.81\right)$. An analysis of simple main effects for each factor was performed with statistical significance after a Bonferroni correction (Table S2). (B) Primary root length is influenced by NO and sugar. Primary root length of 7-day-old seedlings grown on MS-Root supplemented with either $2 \%(w / v)$ glucose or $0.75 \%(w / v)$ sucrose $(n=50)$. The diagram shows data between the lower $(\mathrm{Q} 1)$ and upper $(\mathrm{Q} 3)$ quartiles, the median and the mean $(\mathrm{x})$ for each genotype. Common letters $(\mathrm{a}-\mathrm{f})$ indicate there are no significant statistical differences as determined by Welch's one-way ANOVA with post-hoc Games-Howell test $\left(\mathrm{F}_{(7,571)}=203.57, p<0.001\right)$.

While the differences in NO levels are greater in the presence of glucose, the mutants also overproduce NO when grown with sucrose as a carbon source. cue1-5 was the allele which exhibited greater DAF fluorescence, with $2.27 \pm 0.05$ a.f.u./ $\mu$ g protein in glucose and $1.48 \pm 0.01$ a.f.u./ $\mu$ g protein in sucrose. Compared to its control Col-0, this meant a $46 \%$ increase in NO content when grown with glucose, and a $23 \%$ increase in the presence of sucrose. cue1- 1 also showed a significant enhancement in NO levels compared to its control pOCA108, with $1.81 \pm 0.14$ a.f.u./ $\mu$ g protein in glucose compared

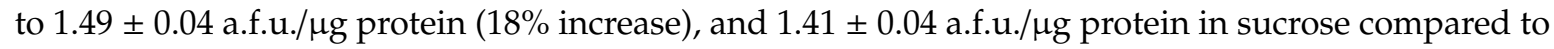
$1.19 \pm 0.03$ a.f.u./ $\mu$ g protein ( $16 \%$ increase).

Since the mutants present an increased NO content in these growth conditions, we decided to measure primary root length to check whether there was a link between the carbon source, NO content, and root length in cue1 mutants. We found that the root length of cue1-5 and cue1-1 was indeed significantly shorter (Figure 5B, Table S1). After 7 days of growth, cue1-5 had a $1.2 \pm 0.06 \mathrm{~cm}$ root in sucrose, which meant a $32 \%$ reduction compared to Col-0, with $1.78 \pm 0.05 \mathrm{~cm}$. The reduction was even more apparent in glucose, where the primary root of cue1-5 only elongated to $0.86 \pm 0.09 \mathrm{~cm}$, a $50 \%$ reduction compared to Col-0, with a $1.73 \pm 0.04 \mathrm{~cm}$ root. Primary root growth was also inhibited in cue1-1 with respect to pOCA108, in sucrose $(1.10 \pm 0.06 \mathrm{~cm}$ compared to $1.85 \pm 0.06 \mathrm{~cm}, 41 \%$ reduction) as well as in glucose (1.01 $\pm 0.07 \mathrm{~cm}$ compared to $2.20 \pm 0.07 \mathrm{~cm}, 54 \%$ reduction). Previous studies have suggested that an optimal concentration of $\mathrm{NO}$ is needed for proper root development, and that both excessive and deficient NO levels are detrimental for the plant [32,33], which coincides with our results. Interestingly, the NO content of cue1-5 and cue1-1 in sucrose was similar to the NO content of pOCA108 in glucose, but the root length of the cue1 mutants was vastly different to that of pOCA108, which suggests that both NO content and the sugar available as a carbon source have a role in the modulation of primary root growth.

We also explored the primary root apical meristems of these roots to analyze meristematic cortical cell length, meristem size, and meristem cell number of the mutants (Figure 6, Table S1). Morphological observation showed that all the lines accumulated amyloplasts in the cortical and epidermal cells upwards of the transition zone when they were grown in the presence of glucose (Figure 6A), but not 
in the presence of sucrose, where only cue1-5 and cue1-1 accumulated them (Figure 6B). Furthermore, we noticed that the cue1 mutants presented amyloplasts in the columella stem cell layer, an indication of earlier differentiation. As described in [32], we observed disorganization of the cells surrounding the QC in some of the cue1-1 and cue1-5 plants, especially in the presence of glucose, where the endogenous NO levels were higher.
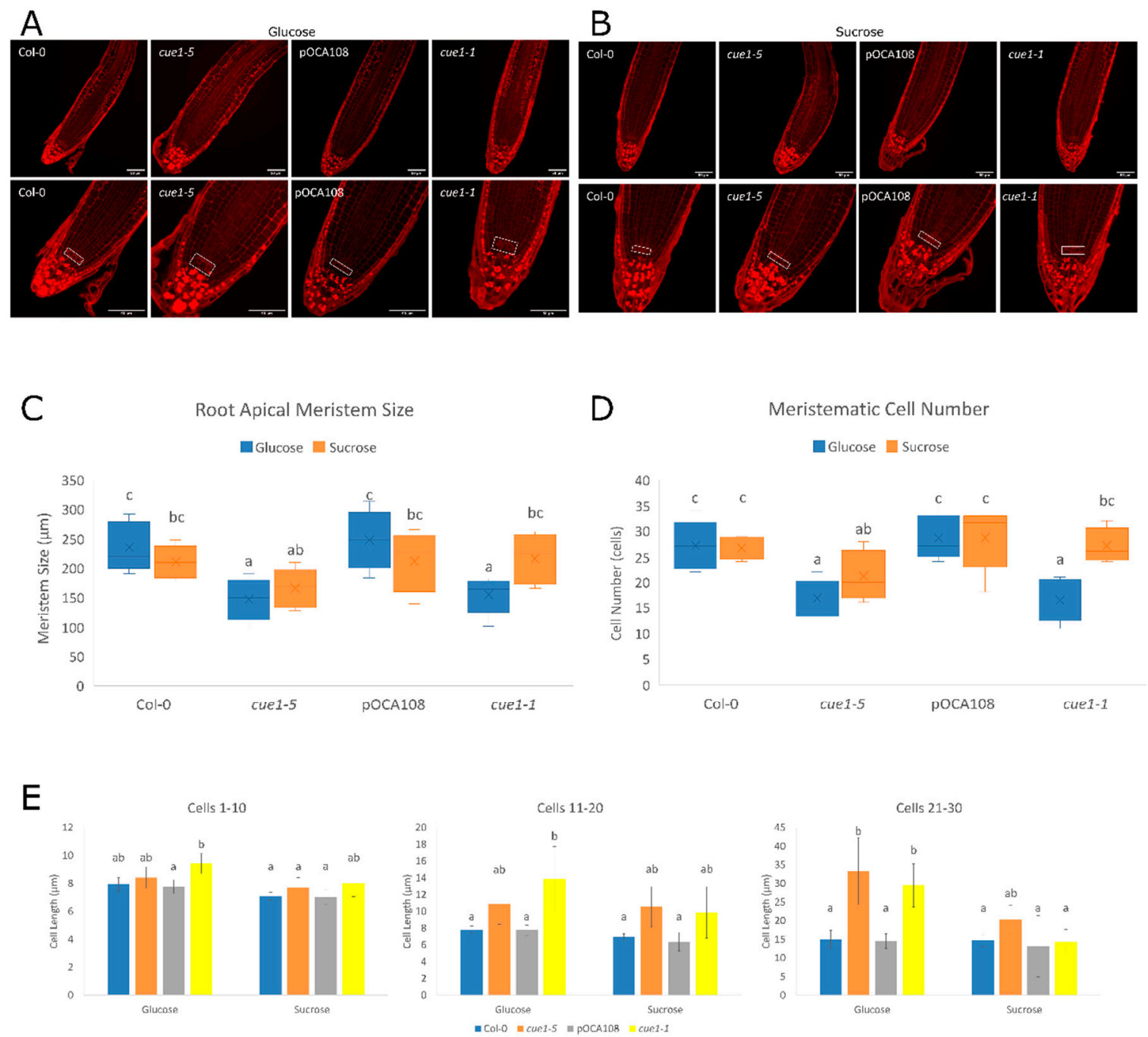

Figure 6. Increased NO causes disorganization of root meristematic stem cells. (A) Representative images of the root meristem of 7-day-old seedlings grown on MS-Root medium supplemented with $2 \%(w / v)$ glucose. (B) Representative images of the root meristem of 7-day-old seedlings grown on MS-Root medium supplemented with $0.75 \%(w / v)$ sucrose. Seedlings were stained with Schiff propidium iodide. Scale bars on bottom left corner correspond to $50 \mu \mathrm{m}$. A white rectangle was drawn around the stem cells. Differentiation parameters were quantified from these images. Statistical differences as determined by two-way ANOVA with post-hoc Tukey's HSD test are represented by different letters $(\mathrm{a}-\mathrm{c})$. $(\mathrm{C})$ Meristematic size $\left(\mathrm{F}_{(3,70)}=6.65, p<0.001\right.$, eta2 $\left.[\mathrm{g}]=0.22\right)$. An analysis of simple main effects for each factor was performed with statistical significance after a Bonferroni correction (Table S2). (D) Number of cells in the root apical meristem $\left(\mathrm{F}_{(3,70)}=6.16, p<0.001\right.$, eta2 $\left.[\mathrm{g}]=0.21\right)$. An analysis of simple main effects for each factor was performed with statistical significance after a Bonferroni correction (Table S2). (E) Bars with common letters (a-c) are not significantly different according to Welch's ANOVA with post-hoc Tukey's HSD test. Average cortical cell sizes are shown for cortical cells 1-10 $\left(\mathrm{F}_{(7,73)}=3.99, p<0.001\right), 11-20\left(\mathrm{~F}_{(7,73)}=5.45, p<0.001\right)$ and $21-30\left(\mathrm{~F}_{(7,73)}=7.23, p<0.001\right)$ counted from the QC. Values represent the mean \pm CI $(n=10)$. 
An analysis of root cortical cells showed that the differences among genotypes were clearer when the plants had been grown with glucose as a carbon source. In those conditions, cue1-5 and cue1-1 differentiated earlier than their controls, since the EDZ occurred closer to the initial cells than in their respective wild-type controls. While a statistical analysis showed that the carbon source only caused a significant difference in meristem size in cue1-5 seedlings (Figure 6C), the variations observed in the rest of the lines supported the divergences observed in the root length of the mutants. Thus, the RAM size in cue1-5 was $21 \%$ smaller than its control in glucose and $18 \%$ smaller in sucrose, while cue1-1 presented only a $2 \%$ reduction in sucrose, but a $15 \%$ decrease in glucose compared to pOCA108. The same was true for the number of cortical cells in the apical meristem, as both cue1-5 and cue1-1 had significantly fewer cells than their respective controls in glucose, but not in sucrose (Figure 6D). This decrease in meristematic cell number was compensated by an increase in meristematic cell length (Figure 6E). These observations support the existence of an interplay between NO content and sugar metabolism in the modulation of primary root growth. At the same time, these results have allowed us to identify cue1 mutants as suitable NO-overproducer plant lines to explore the role of NO during root growth.

\section{Discussion}

\subsection{CUE1 Does Not Directly Contribute to the Rapid NO Synthesis during Seed Imbibition}

$\mathrm{NO}$ is a stimulator molecule in plant photomorphogenesis, as it promotes seed germination and de-etiolation, and inhibits hypocotyl and internode elongation [42]. It has been demonstrated that NO-deficient mutants exhibit increased dormancy, hypersensitivity to ABA during seed germination and seedling establishment, as well as resistance to dehydration [72,73]. The decrease in NO during germination observed in cue1-5 induces a general decline in germination parameters, since it presents a reduced maximum germination rate, decreased uniformity of germination among seeds of the same population, a delay in the initiation of germination and slower germination overall. Moreover, the rest of cue1 mutants were unable to accumulate more NO than their controls at this developmental stage. It has been previously demonstrated that a NO burst is required for proper germination and post-germinative growth $[12,50,74]$, possibly to counteract the inhibitory effect of the ABA-regulated transcription factor ABI5 [45,62,75], which acts as the main regulator of one of the earliest developmental checkpoints to spare the plant from pouring resources into growth when the environmental conditions are not optimal for the development of the seedling $[60,61]$.

During germination, when the quiescent seed reactivates its metabolism, there is a surge in the production of NO that slows down three hours after imbibition [50,74], although NO synthesis can be detected in the aleurone layers as early as fifteen seconds after exogenous nitrate addition [12]. It is thought that the generation of NO by the seed is non-enzymatic because of its quick response, and that this non-enzymatic synthesis requires acidic $\mathrm{pH}$ and the presence of compounds that can act as antioxidants, so this synthesis pathway would be restricted to the apoplast of aleurone cells and maybe local areas of the root during transient acidification caused by alteration of nutrient supply. The aleurone layer fulfills both requisites, as its $\mathrm{pH}$ is usually between 3 and 4 , and its plastids contain proanthocyanidins, phenolic compounds with antioxidant capacity [12]. The early stages of germination coincide with a depletion of oxygen, so it is assumed that seeds are in an anaerobic state until the radicle breaks through the testa, when oxygen gradually returns the seed to aerobic conditions [76]. Thus, it is highly unlikely that the seed can offer the oxidative environment necessary to obtain NO from arginine, and it would explain why cue1 mutants, which are thought to be involved in the oxidative biosynthesis of NO, do not overproduce NO during germination.

Among all studied cue1 mutants, only cue1-5 mutants do not germinate as well as wild-type seeds in response to advantageous environmental conditions even after dormancy is broken by stratification. Our results show that this is due to its inability to de-stabilize ABI5, as shown by its increased ABI5 protein levels. The increase in ABI5 is a direct consequence of the reduced endogenous NO 
content of cue1-5. However, we do not think this is directly caused by the loss of function of CUE1, as the other alleles behave closer to their wild-type controls, both in endogenous NO levels and germination parameters. This mutant line contains an additional transparent testa mutation that affects seed pigmentation, testa solidity and germination [27].

Interestingly, data from the Arabidopsis Seed Coat eFP Browser [77] and the ePlant Browser [78] indicate that the expression of CUE1 in the mature embryo and in dry seeds is almost negligible, but it increases steadily one day after imbibition, well after the rapid production of NO that starts germination. On the other hand, it is highly expressed in the ovaries of the plant, which will give rise to the seed coats. The expression of CUE1 increases in the developing embryo until the walking stick stage, 7-8 days post-anthesis, at the end of the cellularization of the endosperm and before the accumulation of reserves. It is possible, then, that its role in NO generation during germination is carried out during embryo development and seed maturation, likely in an indirect fashion. Since the non-enzymatic synthesis of NO requires proanthocyanidins [12], which are generated as one of the end products of the shikimate pathway, it could be expected that cue1 seeds have less of these polyphenolic compounds available for the quick apoplastic formation of $\mathrm{NO}$ and thus a longer lag phase. Indeed, cue1 mutants have reduced flavonoids, hydroxycinnamic acids, and simple phenolics [27], in agreement with this hypothesis.

\subsection{High Salinity Impairs Germination by Increasing ABI5 and Decreasing NO Levels}

Plants respond to abiotic stress by increasing the production of ABA and reactive oxygen and nitrogen species, so we also tested the behavior of cue1 mutants in response to salt stress during early plant development. Depending on its concentration, NO can protect plants against salt stress by lessening the secondary oxidative stress induced by high salinity $[46,47,79,80]$, or it can enhance sensitivity to the stress if its accumulation is excessive, causing additional nitrosative stress [36,81,82]. It is thought that the protective role of $\mathrm{NO}$ is exerted mainly through redox modification or $S$-nitrosation of ROS scavenging enzymes, antioxidant systems, and respiratory pathways [83]. Reports on the accumulation of NO in $A$. thaliana in response to high salinity are sometimes contradictory, possibly because of differences in biological material, the extent of the stress, and the developmental stage at which the plant was subjected to salt stress $[46,47,53-56,84,85]$.

In our growth conditions and developmental stage, the NO content of the seedlings decreased when seeds had been germinated on MS medium supplemented with $100 \mathrm{mM} \mathrm{NaCl}$, regardless of their genotype and in agreement with [46]. Contrary to other salt stress treatments performed in A. thaliana, this may not be enough to cause secondary nitrosative stress. It has been demonstrated that the induction of $\mathrm{NO}$ by salt requires peroxisomal NO synthase activity [53], which needs oxygen to be able to oxidize arginine. Thus, it is possible that, in the anoxic state of the germinating seed, $100 \mathrm{mM}$ $\mathrm{NaCl}$ is too mild a stress to generate enough ROS for creating the oxidative environment required for the function of NO synthase. Because of the reduced NO levels, germination was equally impaired in all the lines, as evidenced by the analysis of different germination parameters. This was explained by an increase in ABI5 protein levels, which was easily detected after germination during salt stress, since ABI5 is stabilized by ABA and degraded in a NO-mediated process [33], and it accumulates in seeds that undergo salt stress [60]. In fact, ABI5 expression is highly induced by abiotic stress at the transition from mature seeds to seedling growth. Salt delays the decline of ABI5 levels and promotes its expression throughout the seedling, while in unstressed conditions it would be undetectable [86].

\subsection{Initial Seedling Establishment Is Impaired in cue1 Mutants Independently of Their NO Levels}

In addition to the characterization of the role of CUE1 during germination, we explored its role during early post-germinative growth by quantifying the primary root length and exploring the root apical meristem of cue1 mutants 5 das. However, we were unable to find a relationship between their NO content and these parameters, since all cue1 lines showed a significant reduction in root growth independently of the differences in their NO levels. This observation further stresses the need for 
a careful assessment of NO levels when working with NO mutants. Understanding the effect of the loss of a translocator involved in glycolysis and photosynthesis during root development can prove to be quite complex, as phenotypes are the result of an intricate interplay between hormones, other growth regulators, and environmental cues.

Early plant development is mostly supported by the storage reserves found in the endosperm [87], which in A. thaliana cannot last more than 4-5 days and are mostly used to elongate the hypocotyl until it reaches light, when cotyledons start greening and are converted into photosynthetic organs [88]. cue1 mutants have been described to be defective in the maturation of eoplasts to chloroplasts and in the initial establishment of photoautotrophism in the absence of an exogenously supplied metabolizable sugar [24]. Sugars mobilized from the endosperm and synthesized in the green parts of the plant function as energy sources as well as signaling molecules. In particular, photosynthetic sugars delivered from the cotyledons to the root act as interorgan signals to initiate root growth and have a dominant role during the cotyledon stage of seedling development, even over the phytohormone auxin, which is thought to be essential for the regulation of root development [88]. Since all cue1 mutants are photosynthetically defective, we cannot rule out that their initial inability to start root elongation stems from the lack of a photosynthetic signal.

\subsection{Sugars Alter Root Development through Modulation of NO Homeostasis}

After exposure to exogenous NO, the content of several glycolysis intermediates, metabolites of the TCA cycle and intermediates of the Calvin cycle were reduced [70]. On the other hand, the content of sucrose and different monosaccharides, disaccharides, amino and nucleotide sugars increased [70,71]. These metabolic changes are caused by the transcriptional upregulation of glycolytic enzymes and the downregulation of photosynthetic proteins [69], and by the regulation via S-nitrosation of enzymes involved in sugar metabolism, such as ATP synthase, enolase, or phosphoglycerate kinase [71].

CUE1/PPT1 has a central role in sugar metabolism because it is the only source of PEP into the chloroplast and its absence directly impacts carbon partitioning [27,89]. Interestingly, cue1 mutants are unable to establish photoautotrophic growth right after germination and need to be exogenously supplemented with a fixed carbon photoassimilate [24]. These mutants have impaired light signaling and a reduced capacity of de-etiolation [24,26], possibly because they are defective in chloroplast maturation [24]. Essentially, cue1 mutants behave as heterotrophs during early plant development.

cue1 mutants have not been the first NO mutants to be linked to sugar metabolism. noa1, which encodes a cGTPase necessary for assembling plastid ribosomes [90], was initially isolated as a mutant with less endogenous NO content and essential for its production [91]. Interestingly, the levels of NO in noa1 mutants can be partially recovered by exogenous addition of sucrose [92], and the mutant presents chloroplast biogenesis defects [93] and reduced fumarate, even though its energy status and redox potential seem unaffected [92]. The NO deficiency in noa1 was explained as an indirect effect of its reduced ability to generate photosynthates [93]. However, cue1 mutants are also defective in chloroplast biogenesis and contain fewer photoassimilates than wild-type lines, whereas their NO levels are enhanced. Thus, a reduced photosynthetic capacity cannot solely be the reason for reduced NO content in noa1.

We analyzed the endogenous NO status of cue1 mutants in the presence of two different sugars that can be used by the plant as a source of reduced carbon and energy, glucose and sucrose. If a general decrease in reduced carbon availability explained the alteration in NO content, the mutants would be expected to produce the same NO in any case. However, our results showed the differences between cue1 mutants and their controls were greater when the seedlings had been grown in the presence of glucose. Sucrose did not revert the NO overproducing phenotype of cue1 plants, but it did diminish the differences among the lines, as in the case of noa1 [93]. The increased NO production in the presence of glucose in cue1-5 and cue1-1 caused a decrease in primary root elongation rate, meristem size, meristematic cell number, and longer root cell length, corroborating the findings of [29]. These differences were not as obvious when the plants were grown in the presence of sucrose, but the 
root growth of cue1-5 and cue1-1 was still affected. Our findings show that NO accumulation depends on sugar metabolism. Nitrate reductase (NR) is an enzyme that also participates in the production of NO [94] and it has been previously shown that the expression of NIA2, the gene encoding NR, is light-induced, while NR activity is linked to photosynthesis [95]. NR could be a good candidate linking NO homeostasis and carbon metabolism, but, surprisingly, noa1 has higher NR levels [92], while cue mutants have reduced NR activity [26]. Understanding the role of carbon metabolism will help elucidate the molecular mechanisms underlying NO production in plant development, but further experiments are required.

\section{Materials and Methods}

\subsection{Plant Lines}

Arabidopsis thaliana cue1-5 [26], cue1-6 [27] and nox1-1 [23] plants are in the Columbia (Col-0) ecotype background, while cue1-1 [24] is in the Bensheim (Be-0) ecotype background. All cue1 mutants are defective in the CUE1 locus (AT5G33320). The cue1-5 (CS3156) and cue1-6 (CS3168) alleles were generated by mutagenizing a Col-0 population with ethyl methanesulfonate (EMS) [27], while the nox1-1 allele was generated by fast neutron mutagenesis [23]. Additionally, cue1-5 seeds are yellow and lack brown pigments in the seed coat, as the mutant contains an additional transparent testa/glabrous mutation [96]. The cue1-1 allele was generated by mutagenizing a population of line pOCA108-1 with gamma radiation [24]. pOCA108-1 is a single-insertion line that contains the reporter construct pOCA108 on chromosome 2 . This construct contains the alcohol dehydrogenase $(A D H)$ gene under the control of chlorophyll $a / b$ binding protein $(C A B 3)$ promoter, and was transformed into Bensheim line R002, which contains a null mutation in the endogenous $A D H$ gene [24].

\subsection{Plant Growth Conditions}

Seeds grown in vitro were surface sterilized using a bleach solution ( $25 \%$ bleach, $0.1 \%$ Tween). Sterilized seeds were stratified in water for $48-72 \mathrm{~h}$ at $4{ }^{\circ} \mathrm{C}$ to help synchronize germination. Stratified seeds used for root elongation assays and $\mathrm{NO}$ quantification in different carbon sources were grown on plates containing a modified Murashige and Skoog (MS) medium [97] optimized for root growth, MS-Root [2.3 g/L MS (Duchefa Biochemie, Haarlem, The Netherlands), $15 \mathrm{~g} / \mathrm{L}$ agar], supplemented with either sucrose or glucose as indicated. The greater agar content allows for vertical growth of seedlings on the surface of the medium. For the rest of the experiments, plants were grown on plates containing $4.9 \mathrm{~g} / \mathrm{L} \mathrm{MS}, 2 \%$ glucose, $6 \mathrm{~g} / \mathrm{L}$ agar. Stratified seeds used for NO quantification, germination and high salinity assays were grown on plates containing MS medium supplemented with $2 \%$ glucose. To analyze sensitivity to salt stress, MS was supplemented with $100 \mathrm{mM} \mathrm{NaCl}$ (PanReac AppliChem, Darmstadt, Germany). Plants were grown under a $16 \mathrm{~h}$ light $/ 8 \mathrm{~h}$ dark photoperiod at a constant temperature of $21^{\circ} \mathrm{C}$ and $50-60 \%$ humidity.

\subsection{Germination Assays}

Germination was determined as radicle emergence at indicated times. The analysis of germination parameters was carried out using the GERMINATOR software [58]. The parameters used are $t_{50}$, the time it takes for $50 \%$ of the viable seeds to germinate, for speed of germination, and $U_{7525}$, the elapsed time from $25 \%$ to $75 \%$ of the viable seeds to germinate, for uniformity of germination. Germination was also represented with a time course graph as cumulative germination.

\subsection{Western Blotting}

Total proteins were extracted from 4-day-old stratified and imbibed seeds (500-600 per genotype) for western blot analysis. Tissue was homogenized using a Silamat S6 homogenizer (Ivoclar Vivadent, Madrid, Spain) until all tissue was completely powdered. Samples were incubated with an extraction buffer containing $100 \mathrm{mM}$ Tris- $\mathrm{HCl}, 150 \mathrm{mM} \mathrm{NaCl}, 0.25 \%$ NP-40 and 1× cOmplete EDTA-free Protease 
Inhibitor Cocktail (Sigma, Saint Louis, MO, USA). Protein concentration was determined by the Bio-Rad Protein Assay (Bio-Rad, Hercules, CA, USA) based on the Bradford method [98]. An amount of 90 $\mu \mathrm{g}$ of total protein was loaded per well in 10\% SDS-acrylamide/bisacrylamide gel electrophoresis using Tris-glycine-SDS buffer. Proteins were electrophoretically transferred to an Immobilon-P polyvinylidene difluoride membrane (Merck Millipore, Burlington, VT, USA) using the semi-dry Trans-Blot Turbo Transfer system (Bio-Rad). Membranes were blocked in Tris-buffered saline- $0.1 \%$ Tween 20 containing 5\% Blocking Agent and probed with antibodies diluted in blocking buffer. Anti-ABI5 Purified Rabbit Immunoglobulin (Biomedal, Sevilla, Spain, 1:10,000) and anti-Actin clone 10-B3 Purified Mouse Immunoglobulin (Sigma-Aldrich, A0480, 1:10,000) antibodies were used in the Western blot analyses. Detection was performed using ECL Advance Western Blotting Detection Kit (Amersham, Chicago, IL, USA) and the chemiluminescence was detected using an Intelligent Dark-Box II, LAS-1000 scanning system (Fujifilm, Tokyo, Japan).

\subsection{Detection of NO Production}

Freshly prepared protein extracts prepared as for western blotting were used to assay NO content. An amount of $20 \mu \mathrm{L}$ of each protein extract was incubated with $180 \mu \mathrm{L}$ of a solution containing $10 \mu \mathrm{M}$ of DAF-FM DA (Sigma-Aldrich) in 50 mM HEPES buffer $\mathrm{pH} 7.5$ in microtiter plates, following the method described in [49]. Samples were incubated at $37^{\circ} \mathrm{C}$ for $2 \mathrm{~h}$ in the dark. After incubation, the emitted fluorescence of each well was measured in a Varioskan LUX Multimode Microplate Reader (ThermoFisher Scientific, Waltham, MA, USA). Samples were normalized by their total protein content (Table S3) and against a control condition in each experiment. Blanks included in all experiments behaved similarly and emitted a negligible signal, that was subtracted from all experimental samples.

Detection of NO through confocal microscopy was performed using the same experimental conditions and DAF-FM DA staining protocol for the former spectrofluorometry measurements. $\lambda$ scan 500-666 nm was used to set the emission window and FIRE LUT to represent a fluorescence heatmap of intensity.

\subsection{Root Growth Analysis}

After full germination, root growth was captured by scanning plates with an Epson flatbed scanner and a resolution set to 600 ppi. Primary root length of individual seedlings was then measured using Fiji [99]. Average root elongation rate $(\mathrm{mm} / \mathrm{d})$ was calculated as an average of daily root elongation rates following the protocol described in [100].

Primary root apical meristems were analyzed to measure meristematic cortical cell length $(\mu \mathrm{m})$, meristem size $(\mu \mathrm{m})$, and meristem cell number by performing a propidium iodide (PI) stain following the protocol described in [101]. Root tips were examined using a Leica SP2 confocal microscope with a $40 \times$ oil immersion objective. The resulting image data was processed with semi-automatic image analysis software, Cell-O-Tape [102].

\subsection{Statistical Analysis}

For each dataset, the distribution was initially assessed by plotting all the values of the dependent variable as a histogram. Normality and homoscedasticity of the populations were determined using the Shapiro-Wilk and Levene's tests, respectively. An appropriate statistical model was then selected depending on the number of independent variables, the distribution of the dependent variable, and whether it was categorical or continuous. To account for type I error, data was presented with a 95\% confidence interval (CI). Generalized linear models (ANOVAs) and Pearson's product-moment correlation tests were performed using R Statistical Software ( $\mathrm{R}$ version 4.0.2, R Foundation for Statistical Computing) [103] in the RStudio environment (RStudio version 1.3.959, PBC) [104]. Excel (Microsoft Office 365 ProPlus, v.1902) was used for other statistical tests and graph plotting. The statistical power of the chosen tests was performed using G*Power v.3.1.9.2 (Franz Faul, Universität Kiel). 


\section{Conclusions}

Despite the ample research performed to elucidate the role of NO during development, no systematic study of the production of $\mathrm{NO}$ during different developmental stages has been performed to date. The reports discussed in this article point to specific roles that would require tightly controlled spatio-temporal NO accumulation. To our knowledge, the only analysis comparing the production of NO at two different plant developmental stages was published using Medicago truncatula [105]. In this study it was shown that senescing plants had an increased sensitivity to nitrosative stress, as well as repression of nitrate uptake and NR activity, suggesting that accumulation of NO and regulation of its homeostasis depends on the developmental stage. Our results support this statement, as a careful characterization of the NO production of different cue1 mutants, routinely used as NO overproducer mutants, proved that cue1 mutants do not accumulate NO during early plant development, but they do at later stages. Since most NO mutants are defective in proteins involved in primary metabolism $[68,106]$, we recommend that NO quantification be performed for NO mutants at early developmental stages, given that their alteration of NO homeostasis might stem from unexpected effects of their mutations. In conclusion, our results demonstrate that cue1 is a useful tool to study the physiological functions of $\mathrm{NO}$, since this mutant accumulates $\mathrm{NO}$ under controlled experimental conditions that require awareness of the developmental stage and growth conditions of the plants, especially in terms of stress trade-off.

Supplementary Materials: The following are available online at http://www.mdpi.com/2223-7747/9/11/1484/s1, Figure S1: (A) Detection of NO by confocal microscopy using root tips of 7-day-old Col-0 seedlings stained with DAF-FM DA incubation after treatment with NO scavenger (cPTIO) and donor (GSNO). cPTIO is able to scavenge DAF and GSNO increases local maxima. (B) DAF fluorescence by confocal microscopy using root tips of 7-day-old seedlings from Col-0, pOCA108 and cue1 alleles grown on MS-Root medium supplemented with either $2 \%(w / v)$ glucose or $0.75 \%(w / v)$ sucrose. FIRE LUT was used as a fluorescence heatmap. Table S1: Sugar and NO affect root meristem size. Meristem size parameters of 7-day-old seedlings grown on MS-Root medium supplemented with either $2 \%$ glucose or $0.75 \%$ sucrose. Values represent the mean $\pm \mathrm{CI}(\mathrm{N}=104)$. All units were in $\mu \mathrm{m}$ and 10 roots were analyzed per genotype and carbon source. Table S2: Two-way ANOVA statistical parameters and simple main effects results. Table S3: Protein content of 4-day-old and 7-day-old seedlings $(\mu \mathrm{g} / \mathrm{mL})$.

Author Contributions: Conceptualization, T.L., L.S. and O.L.; methodology, T.L., L.S., I.S.-V. and O.L.; validation, T.L., L.S., I.S.-V. and O.L.; formal analysis, T.L.; investigation, T.L. and I.S.-V.; resources, O.L.; writing-original draft preparation, T.L.; writing — review and editing, T.L., I.S.-V., L.S., O.L.; visualization, T.L.; supervision, L.S. and O.L.; project administration, O.L.; funding acquisition, O.L. All authors have read and agreed to the published version of the manuscript.

Funding: This research was funded by grants BIO2017-85758-R from the Ministerio de Ciencia, Innovación y Universidades (Spain), and SA313P18 from Junta de Castilla y León and Escalera de Excelencia CLU-2018-04 co-funded by the P.O. FEDER of Castilla y León 2014-2020 Spain (to O.L.). Fundación Solórzano FS/16 2019 (to I.S.-V.). T.L. was supported by a FPU predoctoral fellowship awarded by Ministerio de Educación, Cultura y Deporte (Spain), FPU13/05569.

Acknowledgments: We thank Dolores Rodriguez, Walter Dewitte, Isabel Mateos and Pablo Albertos for critical comments of the manuscript and technical assistance, and the Spanish network BIO2015-68957-REDT and RED2018-102397-T for stimulating discussions. We also thank Lucas Frungillo for providing the cue1-6 seeds. nox1 mutant was a kind gift from Zhen-Ming Pei and cue1-1 and cue1-5 were obtained from the Arabidopsis Biological Resource Center (ABRC).

Conflicts of Interest: The authors declare no conflict of interest. The funders had no role in the design of the study; in the collection, analyses, or interpretation of data; in the writing of the manuscript, or in the decision to publish the results.

\section{References}

1. Cueto, M.; Hernández-Perera, O.; Martín, R.; Bentura, M.L.; Rodrigo, J.; Lamas, S.; Golvano, M.P. Presence of nitric oxide synthase activity in roots and nodules of Lupinus albus. FEBS Lett. 1996, 398, 159-164. [CrossRef]

2. Lazalt, A.M.; Beligni, M.V.; Lamattina, L. Nitric oxide preserves the level of chlorophyll in potato leaves infected by Phytophthora infestans. Eur. J. Plant Pathol. 1997, 103, 643. [CrossRef]

3. Delledonne, M.; Xia, Y.; Dixon, R.A.; Lamb, C. Nitric oxide functions as a signal in plant disease resistance. Nature 1998, 394, 585-588. [CrossRef] [PubMed] 
4. Durner, J.; Wendehenne, D.; Klessig, D.F. Defense gene induction in tobacco by nitric oxide, cyclic GMP, and cyclic ADP-ribose. Proc. Natl. Acad. Sci. USA 1998, 95, 10328-10333. [CrossRef]

5. Astier, J.; Gross, I.; Durner, J. Nitric oxide production in plants: An update. J. Exp. Bot. 2018, 69, 3401-3411. [CrossRef]

6. Bruand, C.; Meilhoc, E. Nitric oxide in plants: Pro-or anti-senescence. J. Exp. Bot. 2019, 70, 4419-4427. [CrossRef]

7. Sánchez-Vicente, I.; Fernández-Espinosa, M.G.; Lorenzo, O. Nitric oxide molecular targets: Reprogramming plant development upon stress. J. Exp. Bot. 2019, 70, 4441-4460. [CrossRef]

8. Rai, K.K.; Pandey, N.; Rai, S.P. Salicylic acid and nitric oxide signaling in plant heat stress. Physiol. Plant. 2020, 168, 241-255. [CrossRef]

9. Kapil, V.; Khambata, R.S.; Jones, D.A.; Rathod, K.; Primus, C.; Massimo, G.; Fukuto, J.M.; Ahluwalia, A. The noncanonical pathway for in vitro nitric oxide generation; the nitrate-nitrite-nitric oxide pathway. Pharmacol. Rev. 2020, 72, 692-766. [CrossRef]

10. Jeandroz, S.; Wipf, D.; Stuehr, D.J.; Lamattina, L.; Melkonian, M.; Tian, Z.; Zhu, Y.; Carpenter, E.J.; Wong, G.K.-S.; Wendehenne, D. Occurrence, structure, and evolution of nitric oxide synthase-like proteins in the plant kingdom. Sci. Signal. 2016, 9, re2. [CrossRef]

11. Hasanuzzaman, M.; Oku, H.; Nahar, K.; Bhuyan, M.H.M.B.; Mahmud, J.A.; Baluska, F.; Fujita, M. Nitric oxide-induced salt stress tolerance in plants: ROS metabolism, signaling, and molecular interactions. Plant Biotechnol. Rep. 2018, 12, 77-92. [CrossRef]

12. Bethke, P.C.; Badger, M.R.; Jones, R.L. Apoplastic Synthesis of Nitric Oxide by Plant Tissues. Plant Cell 2004, 16, 332-341. [CrossRef]

13. Begara-Morales, J.C.; Chaki, M.; Valderrama, R.; Sánchez-Calvo, B.; Mata-Pérez, C.; Padilla, M.N.; Corpas, F.J.; Barroso, J.B. Nitric oxide buffering and conditional nitric oxide release in stress response. J. Exp. Bot. 2018, 69, 3425-3438. [CrossRef] [PubMed]

14. Mur, L.A.J.; Mandon, J.; Persijn, S.; Cristescu, S.M.; Moshkov, I.E.; Novikova, G.V.; Hall, M.A.; Harren, F.J.M.; Hebelstrup, K.H.; Gupta, K.J. Nitric oxide in plants: An assessment of the current state of knowledge. AoB Plants 2013, 5, pls052. [CrossRef] [PubMed]

15. Broniowska, K.A.; Diers, A.R.; Hogg, N. S-Nitrosoglutathione. Biochim. Biophys. Acta-Gen. Subj. 2013, 1830, 3173-3181. [CrossRef]

16. Ederli, L.; Reale, L.; Madeo, L.; Ferranti, F.; Gehring, C.; Fornaciari, M.; Romano, B.; Pasqualini, S. NO release by nitric oxide donors in vitro and in planta. Plant Physiol. Biochem. 2009, 47, 42-48. [CrossRef] [PubMed]

17. Melvin, A.C.; Jones, W.M.; Lutzke, A.; Allison, C.L.; Reynolds, M.M. S-Nitrosoglutathione exhibits greater stability than $S$-nitroso- $N$-acetylpenicillamine under common laboratory conditions: A comparative stability study. Nitric Oxide 2019, 92, 18-25. [CrossRef]

18. Feechan, A.; Kwon, E.; Yun, B.-W.; Wang, Y.; Pallas, J.A.; Loake, G.J. A central role for S-nitrosothiols in plant disease resistance. Proc. Natl. Acad. Sci. USA 2005, 102, 8054-8059. [CrossRef] [PubMed]

19. Sakamoto, A.; Ueda, M.; Morikawa, H. Arabidopsis glutathione-dependent formaldehyde dehydrogenase is an $S$-nitrosoglutathione reductase. FEBS Lett. 2002, 515, 20-24. [CrossRef]

20. Lee, U.; Wie, C.; Fernandez, B.O.; Feelisch, M.; Vierling, E. Modulation of nitrosative stress by $S$-nitrosoglutathione reductase is critical for thermotolerance and plant growth in Arabidopsis. Plant Cell 2008, 20, 786-802. [CrossRef]

21. Hebelstrup, K.H.; Jensen, E.Ø. Expression of NO scavenging hemoglobin is involved in the timing of bolting in Arabidopsis thaliana. Planta 2008, 227, 917-927. [CrossRef]

22. Flores, T.; Todd, C.D.; Tovar-Mendez, A.; Dhanoa, P.K.; Correa-Aragunde, N.; Hoyos, M.E.; Brownfield, D.M.; Mullen, R.T.; Lamattina, L.; Polacco, J.C. Arginase-negative mutants of Arabidopsis exhibit increased nitric oxide signaling in root development. Plant Physiol. 2008, 147, 1936-1946. [CrossRef]

23. He, Y.; Tang, R.-H.; Hao, Y.; Stevens, R.D.; Cook, C.W.; Ahn, S.M.; Jing, L.; Yang, Z.; Chen, L.; Guo, F.; et al. Nitric oxide represses the Arabidopsis floral transition. Science 2004, 305, 1968-1971. [CrossRef] [PubMed]

24. Li, H.; Culligan, K.; Dixon, R.A.; Chory, J. CUE1: A Mesophyll Cell-Specific Positive Regulator of Light-Controlled Gene Expression in Arabidopsis. Plant Cell 1995, 7, 1599-1610. [CrossRef]

25. López-Juez, E.; Jarvis, R.P.; Takeuchi, A.; Page, A.M.; Chory, J. New Arabidopsis cue mutants suggest a close connection between plastid and phytochrome regulation of nuclear gene expression. Plant Physiol. 1998, 118, 803-815. [CrossRef] 
26. Vinti, G.; Fourrier, N.; Bowyer, J.R.; López-Juez, E. Arabidopsis cue mutants with defective plastids are impaired primarily in the photocontrol of expression of photosynthesis-associated nuclear genes. Plant Mol. Biol. 2005, 57, 343-357. [CrossRef] [PubMed]

27. Streatfield, S.J.; Weber, A.; Kinsman, E.A.; Häusler, R.E.; Li, J.; Post-Beittenmiller, D.; Kaiser, W.M.; Pyke, K.A.; Chory, J. The Phosphoenolpyruvate/Phosphate Translocator Is Required for Phenolic Metabolism, Palisade Cell Development, and Plastid-Dependent Nuclear Gene Expression. Plant Cell 1999, 11, 1609-1621. [CrossRef]

28. Fischer, K.; Kammerer, B.; Gutensohn, M.; Arbinger, B.; Weber, A.; Häusler, R.E.; Flügge, U.I. A new class of plastidic phosphate translocators: A putative link between primary and secondary metabolism by the phosphoenolpyruvate/phosphate antiporter. Plant Cell 1997, 9, 453-462. [CrossRef]

29. Sanz, L.; Albertos, P.; Mateos, I.; Sánchez-Vicente, I.; Lechón, T.; Fernández-Marcos, M.; Lorenzo, O. Nitric oxide (NO) and phytohormones crosstalk during early plant development. J. Exp. Bot. 2015, 66, 2857-2868. [CrossRef]

30. Petó, A.; Lehotai, N.; Lozano-Juste, J.; León, J.; Tari, I.; Erdei, L.; Kolbert, Z. Involvement of nitric oxide and auxin in signal transduction of copper-induced morphological responses in Arabidopsis seedlings. Ann. Bot. 2011, 108, 449-457. [CrossRef] [PubMed]

31. Fu, Z.-W.; Wang, Y.-L.; Lu, Y.-T.; Yuan, T.-T. Nitric oxide is involved in stomatal development by modulating the expression of stomatal regulator genes in Arabidopsis. Plant Sci. 2016, 252, 282-289. [CrossRef]

32. Fernández-Marcos, M.; Sanz, L.; Lewis, D.R.; Muday, G.K.; Lorenzo, O. Nitric oxide causes root apical meristem defects and growth inhibition while reducing PIN-FORMED 1 (PIN1)-dependent acropetal auxin transport. Proc. Natl. Acad. Sci. USA 2011, 108, 18506-18511. [CrossRef]

33. Sanz, L.; Fernández-Marcos, M.; Modrego, A.; Lewis, D.R.; Muday, G.K.; Pollmann, S.; Dueñas, M.; Santos-Buelga, C.; Lorenzo, O. Nitric Oxide Plays a Role in Stem Cell Niche Homeostasis through Its Interaction with Auxin. Plant Physiol. 2014, 166, 1972-1984. [CrossRef] [PubMed]

34. Wang, J.; Wang, Y.; Lv, Q.; Wang, L.; Du, J.; Bao, F.; He, Y.-K. Nitric oxide modifies root growth by S-nitrosylation of plastidial glyceraldehyde-3-phosphate dehydrogenase. Biochem. Biophys. Res. Commun. 2017, 488, 88-94. [CrossRef]

35. Bai, S.; Li, M.; Yao, T.; Wang, H.; Zhang, Y.; Xiao, L.; Wang, J.; Zhang, Z.; Hu, Y.; Liu, W.; et al. Nitric oxide restrain root growth by DNA damage induced cell cycle arrest in Arabidopsis thaliana. Nitric Oxide 2012, 26, 54-60. [CrossRef]

36. Liu, W.-Z.; Kong, D.-D.; Gu, X.-X.; Gao, H.-B.; Wang, J.-Z.; Xia, M.; Gao, Q.; Tian, L.-L.; Xu, Z.-H.; Bao, F.; et al. Cytokinins can act as suppressors of nitric oxide in Arabidopsis. Proc. Natl. Acad. Sci. USA 2013, 110, 1548-1553. [CrossRef]

37. Yang, L.; Ji, J.; Wang, H.; Harris-Shultz, K.R.; Abd Allah, E.F.; Luo, Y.; Guan, Y.; Hu, X. Carbon Monoxide Interacts with Auxin and Nitric Oxide to Cope with Iron Deficiency in Arabidopsis. Front. Plant Sci. 2016, 7, 112. [CrossRef]

38. Pető, A.; Lehotai, N.; Feigl, G.; Tugyi, N.; Ördög, A.; Gémes, K.; Tari, I.; Erdei, L.; Kolbert, Z. Nitric oxide contributes to copper tolerance by influencing ROS metabolism in Arabidopsis. Plant Cell Rep. 2013, 32, 1913-1923. [CrossRef]

39. Yun, B.-W.; Feechan, A.; Yin, M.; Saidi, N.B.B.; Le Bihan, T.; Yu, M.; Moore, J.W.; Kang, J.-G.; Kwon, E.; Spoel, S.H.; et al. S-nitrosylation of NADPH oxidase regulates cell death in plant immunity. Nature 2011, 478, 264-268. [CrossRef]

40. Yun, B.-W.; Skelly, M.J.; Yin, M.; Yu, M.; Mun, B.-G.; Lee, S.-U.; Hussain, A.; Spoel, S.H.; Loake, G.J. Nitric oxide and $S$-nitrosoglutathione function additively during plant immunity. New Phytol. 2016, 211, 516-526. [CrossRef] [PubMed]

41. Kneeshaw, S.; Gelineau, S.; Tada, Y.; Loake, G.J.; Spoel, S.H. Selective Protein Denitrosylation Activity of Thioredoxin-h5 Modulates Plant Immunity. Mol. Cell 2014, 56, 153-162. [CrossRef]

42. Beligni, M.V.; Lamattina, L. Nitric oxide stimulates seed germination and de-etiolation, and inhibits hypocotyl elongation, three light-inducible responses in plants. Planta 2000, 210, 215-221. [CrossRef] [PubMed]

43. Bethke, P.C.; Libourel, I.G.L.; Reinöhl, V.; Jones, R.L. Sodium nitroprusside, cyanide, nitrite, and nitrate break Arabidopsis seed dormancy in a nitric oxide-dependent manner. Planta 2006, 223, 805-812. [CrossRef]

44. Bethke, P.C.; Libourel, I.G.L.; Jones, R.L. Nitric oxide reduces seed dormancy in Arabidopsis. J. Exp. Bot. 2006, 57, 517-526. [CrossRef] 
45. Albertos, P.; Romero-Puertas, M.C.; Tatematsu, K.; Mateos, I.; Sánchez-Vicente, I.; Nambara, E.; Lorenzo, O. $S$-nitrosylation triggers ABI5 degradation to promote seed germination and seedling growth. Nat. Commun. 2015, 6, 8669. [CrossRef]

46. Zhao, M.-G.; Tian, Q.-Y.; Zhang, W.-H. Nitric Oxide Synthase-Dependent Nitric Oxide Production Is Associated with Salt Tolerance in Arabidopsis. Plant Physiol. 2007, 144, 206-217. [CrossRef]

47. Shi, H.-T.; Li, R.-J.; Cai, W.; Liu, W.; Wang, C.-L.; Lu, Y.-T. Increasing Nitric Oxide Content in Arabidopsis thaliana by Expressing Rat Neuronal Nitric Oxide Synthase Resulted in Enhanced Stress Tolerance. Plant Cell Physiol. 2012, 53, 344-357. [CrossRef] [PubMed]

48. Shi, H.; Liu, W.; Wei, Y.; Ye, T. Integration of auxin/indole-3-acetic acid 17 and RGA-LIKE3 confers salt stress resistance through stabilization by nitric oxide in Arabidopsis. J. Exp. Bot. 2017, 68, 1239-1249. [CrossRef] [PubMed]

49. Pérez-Chaca, M.V.; Rodríguez-Serrano, M.; Molina, A.S.; Pedranzani, H.E.; Zirulnik, F.; Sandalio, L.M.; Romero-Puertas, M.C. Cadmium induces two waves of reactive oxygen species in Glycine max (L.) roots. Plant. Cell Environ. 2014, 37, 1672-1687. [CrossRef]

50. Liu, Y.; Shi, L.; Ye, N.; Liu, R.; Jia, W.; Zhang, J. Nitric oxide-induced rapid decrease of abscisic acid concentration is required in breaking seed dormancy in Arabidopsis. New Phytol. 2009, 183, 1030-1042. [CrossRef]

51. Bethke, P.; Gubler, F.; Jacobsen, J.; Jones, R. Dormancy of Arabidopsis seeds and barley grains can be broken by nitric oxide. Planta 2004, 219, 847-855. [CrossRef]

52. Li, X.; Pan, Y.; Chang, B.; Wang, Y.; Tang, Z. NO Promotes Seed Germination and Seedling Growth Under High Salt May Depend on EIN3 Protein in Arabidopsis. Front. Plant Sci. 2015, 6, 1203. [CrossRef] [PubMed]

53. Corpas, F.J.; Hayashi, M.; Mano, S.; Nishimura, M.; Barroso, J.B. Peroxisomes are required for in vivo nitric oxide accumulation in the cytosol following salinity stress of Arabidopsis plants. Plant Physiol. 2009, 151, 2083-2094. [CrossRef]

54. Wang, Y.; Ries, A.; Wu, K.; Yang, A.; Crawford, N.M. The Arabidopsis prohibitin gene PHB3 functions in nitric oxide-mediated responses and in hydrogen peroxide-induced nitric oxide accumulation. Plant Cell 2010, 22, 249-259. [CrossRef]

55. Lin, Y.; Yang, L.; Paul, M.; Zu, Y.; Tang, Z. Ethylene promotes germination of Arabidopsis seed under salinity by decreasing reactive oxygen species: Evidence for the involvement of nitric oxide simulated by sodium nitroprusside. Plant Physiol. Biochem. 2013, 73, 211-218. [CrossRef]

56. Zhou, S.; Jia, L.; Chu, H.; Wu, D.; Peng, X.; Liu, X.; Zhang, J.; Zhao, J.; Chen, K.; Zhao, L. Arabidopsis CaM1 and CaM4 promote nitric oxide production and salt resistance by inhibiting $S$-Nitrosoglutathione Reductase via direct binding. PLoS Genet. 2016, 12, e1006255. [CrossRef]

57. Thomson, A.J.; El-Kassaby, Y.A. Interpretation of seed-germination parameters. New For. 1993, 7, $123-132$. [CrossRef]

58. Joosen, R.V.L.; Kodde, J.; Willems, L.A.J.; Ligterink, W.; van der Plas, L.H.W.; Hilhorst, H.W.M. GERMINATOR: A software package for high-throughput scoring and curve fitting of Arabidopsis seed germination. Plant J. 2010, 62, 148-159. [CrossRef]

59. Nambara, E.; Okamoto, M.; Tatematsu, K.; Yano, R.; Seo, M.; Kamiya, Y. Abscisic acid and the control of seed dormancy and germination. Seed Sci. Res. 2010, 20, 55-67. [CrossRef]

60. Lopez-Molina, L.; Mongrand, S.; Chua, N.H. A postgermination developmental arrest checkpoint is mediated by abscisic acid and requires the ABI5 transcription factor in Arabidopsis. Proc. Natl. Acad. Sci. USA 2001, 98, 4782-4787. [CrossRef]

61. Lopez-Molina, L.; Mongrand, S.; McLachlin, D.T.; Chait, B.T.; Chua, N.-H. ABI5 acts downstream of ABI3 to execute an ABA-dependent growth arrest during germination. Plant J. 2002, 32, 317-328. [CrossRef]

62. Gibbs, D.J.; Md Isa, N.; Movahedi, M.; Lozano-Juste, J.; Mendiondo, G.M.; Berckhan, S.; Marín de la Rosa, N.; Vicente Conde, J.; Sousa Correia, C.; Pearce, S.P.; et al. Nitric Oxide Sensing in Plants Is Mediated by Proteolytic Control of Group VII ERF Transcription. Mol. Cell 2014, 53, 369-379. [CrossRef]

63. Dinneny, J.R. Traversing organizational scales in plant salt-stress responses. Curr. Opin. Plant Biol. 2015, 23, 70-75. [CrossRef] [PubMed]

64. Bai, S.; Yao, T.; Li, M.; Guo, X.; Zhang, Y.; Zhu, S.; He, Y. PIF3 is involved in the primary root growth inhibition of Arabidopsis induced by nitric oxide in the light. Mol. Plant 2014, 7, 616-625. [CrossRef] 
65. Krasylenko, Y.A.; Yemets, A.I.; Blume, Y.B. Nitric oxide synthase inhibitor L-NAME affects Arabidopsis root growth, morphology, and microtubule organization. Cell Biol. Int. 2017, 43, 1049-1055. [CrossRef] [PubMed]

66. Sozzani, R.; Iyer-Pascuzzi, A. Postembryonic control of root meristem growth and development. Curr. Opin. Plant Biol. 2014, 17, 7-12. [CrossRef]

67. Cederholm, H.M.; Iyer-Pascuzzi, A.S.; Benfey, P.N. Patterning the primary root in Arabidopsis. Wiley Interdiscip. Rev. Dev. Biol. 2012, 1, 675-691. [CrossRef]

68. Gas, E.; Flores-Pérez, U.; Sauret-Güeto, S.; Rodríguez-Concepción, M. Hunting for plant nitric oxide synthase provides new evidence of a central role for plastids in nitric oxide metabolism. Plant Cell 2009, 21, 18-23. [CrossRef]

69. Hu, W.-J.; Chen, J.; Liu, T.-W.; Liu, X.; Chen, J.; Wu, F.-H.; Wang, W.-H.; He, J.-X.; Xiao, Q.; Zheng, H.-L. Comparative proteomic analysis on wild type and nitric oxide-overproducing mutant (nox1) of Arabidopsis thaliana. Nitric Oxide 2014, 36, 19-30. [CrossRef]

70. León, J.; Costa, Á.; Castillo, M.-C. Nitric oxide triggers a transient metabolic reprogramming in Arabidopsis. Sci. Rep. 2016, 6, 37945. [CrossRef]

71. Zhang, Z.-W.; Luo, S.; Zhang, G.-C.; Feng, L.-Y.; Zheng, C.; Zhou, Y.-H.; Du, J.-B.; Yuan, M.; Chen, Y.-E.; Wang, C.-Q.; et al. Nitric oxide induces monosaccharide accumulation through enzyme $S$-nitrosylation. Plant Cell Environ. 2017, 40, 1834-1848. [CrossRef] [PubMed]

72. Lozano-Juste, J.; León, J. Enhanced abscisic acid-mediated responses in nia1nia2noa1-2 triple mutant impaired in NIA/NR- and AtNOA1-dependent nitric oxide biosynthesis in Arabidopsis. Plant Physiol. 2010, 152, 891-903. [CrossRef]

73. Wimalasekera, R.; Villar, C.; Begum, T.; Scherer, G.F.E. COPPER AMINE OXIDASE1 (CuAO1) of Arabidopsis thaliana contributes to abscisic acid- and polyamine-induced nitric oxide biosynthesis and abscisic acid signal transduction. Mol. Plant 2011, 4, 663-678. [CrossRef]

74. Ma, Z.; Marsolais, F.; Bykova, N.V.; Igamberdiev, A.U. Nitric Oxide and Reactive Oxygen Species Mediate Metabolic Changes in Barley Seed Embryo during Germination. Front. Plant Sci. 2016, 7, 138. [CrossRef]

75. Wang, P.; Zhu, J.-K.; Lang, Z. Nitric oxide suppresses the inhibitory effect of abscisic acid on seed germination by S-nitrosylation of SnRK2 proteins. Plant Signal. Behav. 2015, 10, e1031939. [CrossRef]

76. Bewley, J.D. Seed germination and dormancy. Plant Cell. 1997, 9, 1055-1066. [CrossRef]

77. Dean, G.; Cao, Y.; Xiang, D.; Provart, N.J.; Ramsay, L.; Ahad, A.; White, R.; Selvaraj, G.; Datla, R.; Haughn, G. Analysis of gene expression patterns during seed coat development in Arabidopsis. Mol. Plant 2011, 4, 1074-1091. [CrossRef]

78. Waese, J.; Fan, J.; Pasha, A.; Yu, H.; Fucile, G.; Shi, R.; Cumming, M.; Kelley, L.A.; Sternberg, M.J.; Krishnakumar, V.; et al. ePlant: Visualizing and Exploring Multiple Levels of Data for Hypothesis Generation in Plant Biology. Plant Cell 2017, 29, 1806-1821. [CrossRef]

79. Zhao, M.; Zhao, X.; Wu, Y.; Zhang, L. Enhanced sensitivity to oxidative stress in an Arabidopsis nitric oxide synthase mutant. J. Plant Physiol. 2007, 164, 737-745. [CrossRef] [PubMed]

80. Du, S.-T.; Liu, Y.; Zhang, P.; Liu, H.-J.; Zhang, X.-Q.; Zhang, R.-R. Atmospheric application of trace amounts of nitric oxide enhances tolerance to salt stress and improves nutritional quality in spinach (Spinacia oleracea L.). Food Chem. 2015, 173, 905-911. [CrossRef]

81. Valderrama, R.; Corpas, F.J.; Carreras, A.; Fernández-Ocaña, A.; Chaki, M.; Luque, F.; Gómez-Rodríguez, M.V.; Colmenero-Varea, P.; del Río, L.A.; Barroso, J.B. Nitrosative stress in plants. FEBS Lett. 2007, 581, $453-461$. [CrossRef]

82. Poór, P.; Kovács, J.; Borbély, P.; Takács, Z.; Szepesi, Á.; Tari, I. Salt stress-induced production of reactive oxygen- and nitrogen species and cell death in the ethylene receptor mutant Never ripe and wild type tomato roots. Plant Physiol. Biochem. 2015, 97,313-322. [CrossRef]

83. Fancy, N.N.; Bahlmann, A.-K.; Loake, G.J. Nitric oxide function in plant abiotic stress. Plant. Cell Environ. 2017, 40, 462-472. [CrossRef] [PubMed]

84. Foresi, N.; Mayta, M.L.; Lodeyro, A.F.; Scuffi, D.; Correa-Aragunde, N.; García-Mata, C.; Casalongué, C.; Carrillo, N.; Lamattina, L. Expression of the tetrahydrofolate-dependent nitric oxide synthase from the green alga Ostreococcus tauri increases tolerance to abiotic stresses and influences stomatal development in Arabidopsis. Plant J. 2015, 82, 806-821. [CrossRef] 
85. Mata-Pérez, C.; Begara-Morales, J.C.; Chaki, M.; Sánchez-Calvo, B.; Valderrama, R.; Padilla, M.N.; Corpas, F.J.; Barroso, J.B. Protein Tyrosine Nitration during Development and Abiotic Stress Response in Plants. Front. Plant Sci. 2016, 7, 1699. [CrossRef]

86. Brocard, I.M.; Lynch, T.J.; Finkelstein, R.R. Regulation and role of the Arabidopsis Abscisic Acid-Insensitive 5 gene in abscisic acid, sugar, and stress response. Plant Physiol. 2002, 129, 1533-1543. [CrossRef] [PubMed]

87. Eastmond, P.J.; Germain, V.; Lange, P.R.; Bryce, J.H.; Smith, S.M.; Graham, I.A. Postgerminative growth and lipid catabolism in oilseeds lacking the glyoxylate cycle. Proc. Natl. Acad. Sci. USA 2000, 97, 5669-5674. [CrossRef]

88. Kircher, S.; Schopfer, P. Photosynthetic sucrose acts as cotyledon-derived long-distance signal to control root growth during early seedling development in Arabidopsis. Proc. Natl. Acad. Sci. USA 2012, 109, 11217-11221. [CrossRef]

89. Voll, L.; Hausler, R.E.; Hecker, R.; Weber, A.; Weissenbock, G.; Fiene, G.; Waffenschmidt, S.; Flügge, U.-I. The phenotype of the Arabidopsis cue1 mutant is not simply caused by a general restriction of the shikimate pathway. Plant J. 2003, 36, 301-317. [CrossRef]

90. Moreau, M.; Lee, G.I.; Wang, Y.; Crane, B.R.; Klessig, D.F. AtNOS/AtNOA1 is a functional Arabidopsis thaliana cGTPase and not a nitric-oxide synthase. J. Biol. Chem. 2008, 283, 32957-32967. [CrossRef]

91. Guo, F.-Q.; Okamoto, M.; Crawford, N.M. Identification of a plant nitric oxide synthase gene involved in hormonal signaling. Science 2003, 302, 100-103. [CrossRef] [PubMed]

92. Van Ree, K.; Gehl, B.; Wassim Chehab, E.; Tsai, Y.-C.; Braam, J. Nitric oxide accumulation in Arabidopsis is independent of NOA1 in the presence of sucrose. Plant J. 2011, 68, 225-233. [CrossRef]

93. Flores-Pérez, U.; Sauret-Güeto, S.; Gas, E.; Jarvis, P.; Rodríguez-Concepción, M. A mutant impaired in the production of plastome-encoded proteins uncovers a mechanism for the homeostasis of isoprenoid biosynthetic enzymes in Arabidopsis plastids. Plant Cell 2008, 20, 1303-1315. [CrossRef]

94. Wilkinson, J.Q.; Crawford, N.M. Identification of the Arabidopsis CHL3 gene as the nitrate reductase structural gene NIA2. Plant Cell 1991, 3, 461-471.

95. Bolle, C.; Sopory, S.; Lubberstedt, T.; Klosgen, R.B.; Herrmann, R.G.; Oelmuller, R. The Role of Plastids in the Expression of Nuclear Genes for Thylakoid Proteins Studied with Chimeric $\beta$-Glucuronidase Gene Fusions. Plant Physiol. 1994, 105, 1355-1364. [CrossRef]

96. Redei, G.P. Genetic blocks in the thiamine synthesis of the angiosperm Arabidopsis. Am. J. Bot. 1965, 52, 834-841. [CrossRef]

97. Murashige, T.; Skoog, F. A Revised Medium for Rapid Growth and Bio Assays with Tobacco Tissue Cultures. Physiol. Plant. 1962, 15, 473-497. [CrossRef]

98. Bradford, M.M. A rapid and sensitive method for the quantitation of microgram quantities of protein utilizing the principle of protein-dye binding. Anal. Biochem. 1976, 72, 248-254. [CrossRef]

99. Schindelin, J.; Arganda-Carreras, I.; Frise, E.; Kaynig, V.; Longair, M.; Pietzsch, T.; Preibisch, S.; Rueden, C.; Saalfeld, S.; Schmid, B.; et al. Fiji: An open-source platform for biological-image analysis. Nat. Methods 2012, 9, 676-682. [CrossRef]

100. Rymen, B.; Coppens, F.; Dhondt, S.; Fiorani, F.; Beemster, G.T.S. Kinematic Analysis of Cell Division and Expansion. In Plant Developmental Biology: Methods and Protocols; Hennig, L., Köhler, C., Eds.; Humana Press: Totowa, NJ, USA, 2010; pp. 203-227.

101. Nieuwland, J.; Maughan, S.; Dewitte, W.; Scofield, S.; Sanz, L.; Murray, J.A.H. The D-type cyclin CYCD4;1 modulates lateral root density in Arabidopsis by affecting the basal meristem region. Proc. Natl. Acad. Sci. USA 2009, 106, 22528-22533. [CrossRef]

102. French, A.P.; Wilson, M.H.; Kenobi, K.; Dietrich, D.; Voss, U.; Ubeda-Tomas, S.; Pridmore, T.P.; Wells, D.M. Identifying biological landmarks using a novel cell measuring image analysis tool: Cell-o-Tape. Plant Methods 2012, 8, 7. [CrossRef]

103. R Core Team. R: A Language Environment for Statistical Computing. R Foundation for Statistical Computing. 2020. Available online: http://www.R-project.org (accessed on 29 September 2020).

104. RStudio Team. RStudio. RStudio: Integrated Development for R. RStudio, PBC. 2020. Available online: http://www.rstudio.com (accessed on 29 September 2020). 
105. Antoniou, C.; Filippou, P.; Mylona, P.; Fasoula, D.; Ioannides, I.; Polidoros, A.; Fotopoulos, V. Developmental stage- and concentration-specific sodium nitroprusside application results in nitrate reductase regulation and the modification of nitrate metabolism in leaves of Medicago truncatula plants. Plant Signal. Behav. 2013, 8, e25479. [CrossRef]

106. Igamberdiev, A.U.; Ratcliffe, R.G.; Gupta, K.J. Plant mitochondria: Source and target for nitric oxide. Mitochondrion 2014, 19, 329-333. [CrossRef]

Publisher's Note: MDPI stays neutral with regard to jurisdictional claims in published maps and institutional affiliations.

(C) 2020 by the authors. Licensee MDPI, Basel, Switzerland. This article is an open access article distributed under the terms and conditions of the Creative Commons Attribution (CC BY) license (http://creativecommons.org/licenses/by/4.0/). 